University of Nebraska - Lincoln

DigitalCommons@University of Nebraska - Lincoln

$7-7-2020$

\title{
Legacy and current pesticide residues in Syr Darya, Kazakhstan: Contamination status, seasonal variation and preliminary ecological risk assessment
}

\author{
Daniel D. Snow \\ P. Chakraborty \\ B. Uralbekov \\ B. Satybaldiev \\ J. Brett Sallach
}

See next page for additional authors

Follow this and additional works at: https://digitalcommons.unl.edu/watercenterpubs

Part of the Environmental Indicators and Impact Assessment Commons, Fresh Water Studies Commons, Hydraulic Engineering Commons, Hydrology Commons, Sustainability Commons, and the Water Resource Management Commons

This Article is brought to you for free and open access by the Water Center, The at DigitalCommons@University of Nebraska - Lincoln. It has been accepted for inclusion in Faculty Publications from The Water Center by an authorized administrator of DigitalCommons@University of Nebraska - Lincoln. 


\section{Authors}

Daniel D. Snow, P. Chakraborty, B. Uralbekov, B. Satybaldiev, J. Brett Sallach, L. M. Thornton Hampton, M. Jeffries, A. S. Kolok, and Shannon L. Bartelt-Hunt 


\title{
Legacy and current pesticide residues
} in Syr Darya, Kazakhstan:

\section{Contamination status, seasonal variation and preliminary ecological risk assessment}

\author{
D. D. Snow, ${ }^{1}$ P. Chakraborty, ${ }^{2}$ B. Uralbekov, ${ }^{3}$ B. Satybaldiev, ${ }^{3}$ \\ J. B. Sallach, ${ }^{4}$ L. M. Thornton Hampton, ${ }^{5}$ M. Jeffries, ${ }^{6}$
}

\author{
A. S. Kolok, ${ }^{7}$ and S. B. Bartelt-Hunt ${ }^{8}$
}

1 Water Sciences Laboratory, 202 Water Sciences Laboratory, University of Nebraska, Lincoln, NE, 68583, USA

2 Department of Civil Engineering, SRM Institute of Science and Technology, Kancheepuram District, Tamil Nadu, 603203, India

3 Center of Physical-Chemical Methods of Research and Analysis, Al-Farabi Kazakh National University, Almaty, Kazakhstan

4 Department of Environment and Geography, University of York, Heslington, Y010 5NG, UK

5 Department of Biology, Texas Christian University, and University of North Texas, Denton, TX, 76203, USA

6 Department of Biology, Texas Christian University, Fort Worth, TX, 76129, USA

7 Idaho Water Resources Research Institute, University of Idaho, Moscow, ID, 83844, USA

8 Department of Civil Engineering, University of Nebraska-Lincoln, Lincoln, NE, 68583, USA

Corresponding author - D. D. Snow, 202 Water Sciences Laboratory, 1840 N. 37th Street, Lincoln, NE, 68583-0844, USA.

E-mail addresses — dsnow1@unl.edu (D. D. Snow), paromitc@srmist.edu.in (P. Chakraborty), bulat.ural@gmail.com (B. Uralbekov), bagdat.satybaldiev@gmail.com (B. Satybaldiev), brett.sallach@york.ac.uk (J. B. Sallach), leahthornton@my.unt.edu (L. M. Thornton Hampton), m.jeffries@tcu.edu (M. Jeffries), akolok@idaho.edu (A. S. Kolok), sbartelt@unl.edu (S. B. Bartelt-Hunt).

Published in Water Research 184 (2020) 116141

doi:10.1016/j.watres.2020.116141

Copyright (C) 2020 Elsevier Ltd. Used by permission.

Submitted 25 March 2020; revised 24 June 2020; accepted 2 July 2020; published 7 July 2020. 


\begin{abstract}
The Syr Darya is one of two major rivers in Central Asia supplying critical fresh water to the Aral Sea. In spite of the river's importance and agriculturally-intensive history, few studies have provided a modern evaluation of and the occurrence of pesticide residues potential effects to aquatic life. The primary goal of this investigation was to determine seasonal variations in ambient concentrations of modern and legacy pesticides in bottom sediment and water of the Syr Darya in Kazakhstan (KZ) downstream from an agriculturally-intensive watershed in Uzbekistan. Grab samples and passive samplers were used at five remote sampling stations during June 2015 to provide a baseline for ecotoxicological evaluation. Results were compared with samples collected during and after the agricultural growing season. Polar organic chemical integrative samplers (POCIS) were used in June and calibrated for time-weighted average concentrations of current use pesticides. Among legacy chlorinated pesticides measured in grab samples from the river, lindane $(\gamma-\mathrm{HCH})$ was detected most frequently with the highest concentrations occurring during June. For all the sampling events, residues of lindane $(\gamma-\mathrm{HCH})$ ranged from 0.014 to $0.24 \mu \mathrm{g} / \mathrm{L}$ detected in water samples, are among the highest concentrations reported for rivers globally. Concentrations of $\gamma-\mathrm{HCH}, p, p^{\prime}$-DDE and dieldrin were highest in October when dieldrin concentrations approached $0.4 \mu \mathrm{g} / \mathrm{L}$. Sources of legacy pesticides may be either illicit upstream use or evidence of previous atmospheric contamination of glacial meltwater. Chronic exposure to these residues may lead to ecological risk to lower order organisms in both the sediment and water column.
\end{abstract}

Keywords: Syr Darya, $\gamma$-HCH, $p, p^{\prime}$-DDE, Risk assessment, Aral Sea

\title{
1. Introduction
}

Large-scale diversion of water from the Aral Sea in central Asia is one of the most widely-cited environmental disasters of the last century (Cai et al., 2002). During the 1960s, the government of the former Soviet republics promoted agricultural practices that led to substantial reductions in total discharge of the Amu Darya and the Syr Darya rivers (Fig. 1), primarily to irrigate water-intensive crops including, rice, melons, and cotton (Glantz, 2007). Diversion of the two major rivers feeding the Aral Sea had a highly visible impact, as the total surface area declined to less than $10 \%$ of its historical size and resulted in the near total loss of its commercial fishery (Hecht, 2014).

The southern Amu Darya no longer replenishes the Aral Sea and this part of the basin has substantially reduced in volume, increased in 
salinity, and completely lost its fishery. The northern tributary of Syr Darya now provides limited freshwater replenishment to the northern basin of the Aral Sea, and this basin consequently has fared much better than its southern counterpart. The Kokaral Dam was built in 2005 as an effort to raise the water level in the north basin of the Aral Sea and restore the local fishery (Hecht, 2014). This dam has helped to partially fill the Aral Sea with enough water so that commercial fishing, seeded by fish species that have taken refuge in the lower regions of the Syr Darya, is returning to the region.

Despite the importance of the Syr Darya inflow to the revival of the north basin of the Aral Sea, few recent water quality studies have been conducted on the Syr Darya. Because of the difficulty in regulating use in developing countries, organochlorine pesticides, such as dichlorodiphenyltrichloroethane (DDT) and lindane $(\gamma-\mathrm{HCH})$, may continue to be used upstream (Ali et al., 2014). These persistent, bio-accumulative pesticides were heavily used on irrigated agricultural fields that lie within the Syr Darya watershed (Li, 1999). Consequently, the Syr Darya may carry a significant load of legacy pesticides as well as modern pesticide residues, such as neonicotinoid insecticides into the north basin of the Aral Sea. Legacy pesticides can be significant contributors to exposure of stream biota (Rasmussen et al., 2015), and it is increasingly clear that both modern and legacy contaminants be considered in risk assessment. This paper provides a novel and recent assessment of pesticide concentrations in a remote Central Asian region. Few studies have examined the occurrence and ecological risk of a mixture of legacy and modern pesticides in Central Asia. The goal of this study was to characterize the concentrations of a wide variety of potentially-toxic chemicals in an important freshwater supply for the Aral Sea, and provide a baseline for ecotoxicological evaluation of their effects. Samples were collected during three reconnaissance trips to the Syr Darya during the months of June, August, and October 2015. Passive, in-situ, and grab sampling techniques were tested to evaluate the suitability of alternative means for sampling collection in remote regions such as south Kazakhstan (KZ). A suite of different sampling techniques was employed to evaluate how newer technologies may be adapted to monitoring in remote areas. Results from this study provides a snapshot of chemical contaminant concentrations from samples collected over a single growing season. 


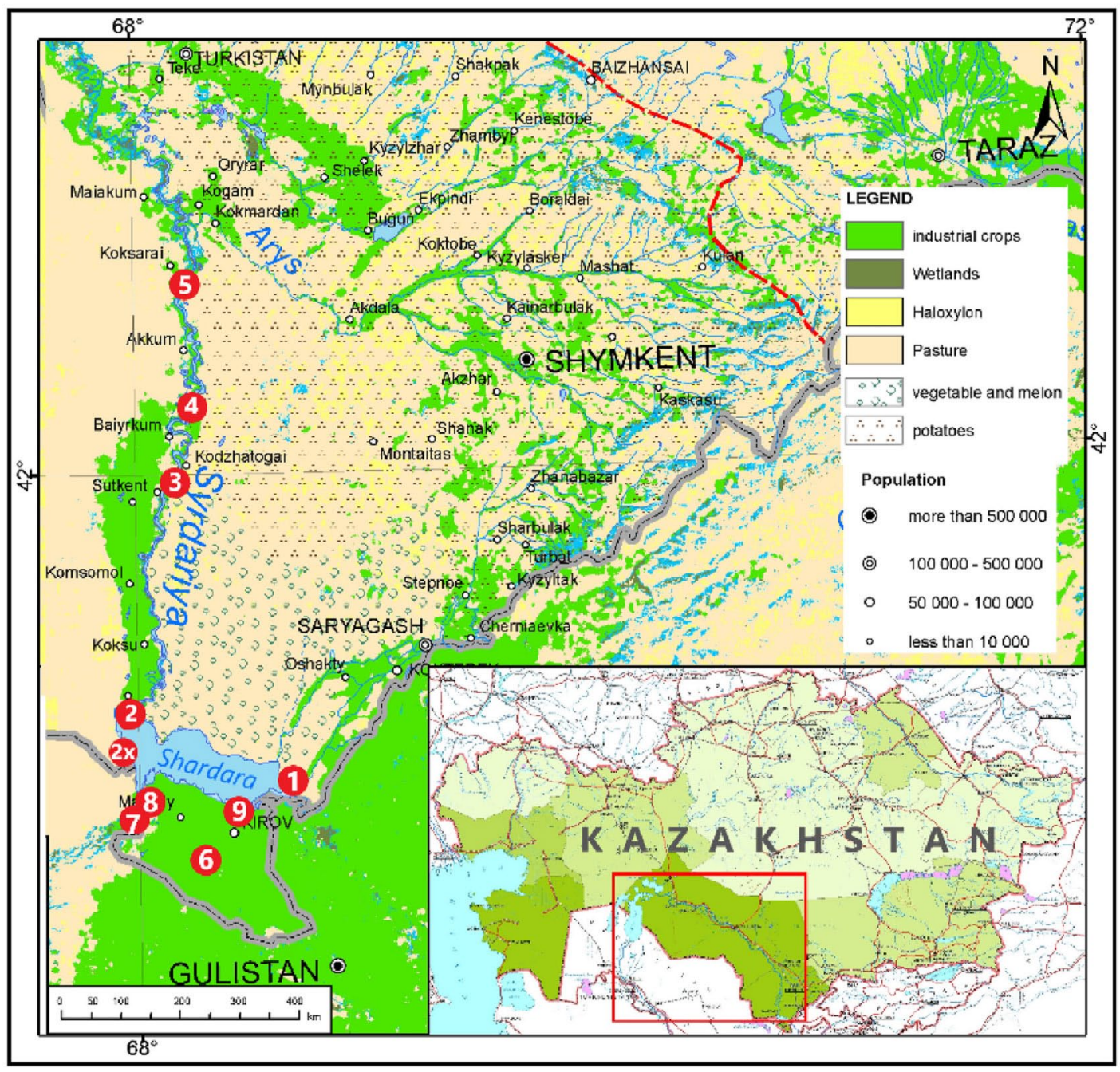

Fig. 1. Map showing the sample locations (numbers in red) along the Syr Darya, Kazakhstan (KZ). River flow is from south to north. All six in-stream locations were sampled in June and October. Coordinates are provided in supplementary material. The Shardara Reservoir is located in the bottom center and site $2 \mathrm{X}$ on the eastern shore.

\section{Materials and methods}

\subsection{Site selection and general sampling}

Preliminary reconnaissance by local researchers identified six accessible locations for sampling and collection of fish tissues along a stretch of the Syr Darya from where it enters Kazakhstan to a point upstream from the Arys River south of Turkistan, KZ (Fig. 1). Sampling trips were 
scheduled to coincide with the beginning, middle, and end of the irrigation season. June sampling results provided a baseline of water quality, while samples collected in August and October coincided with conditions during and at the end of the irrigation season (Frenken, 2013) when increased inputs of persistent pesticide residues from irrigation return flows may be expected. The timing of sampling allowed for an evaluation of changes in contaminant loading from irrigation return flows during a single crop growing season.

The Shardara multi-purpose reservoir (Fig. 1), constructed between 1964 and 1967 on the Syr Darya in Shardara City, KZ, provides storage for both irrigation water and hydroelectric power generation and lies immediately downstream of a boundary with the country of Uzbekistan. The reservoir capacity is approximately $5.2 \times 10^{9} \mathrm{~m}^{3}$ and, depending on upstream precipitation amounts, its volume may be turned over several times annually. Sampling locations were chosen to evaluate the chemical composition of river water as it crossed the border into Kazakhstan and help characterize changes in water quality downstream from the reservoir through a region of irrigated cotton production. The total distance between the Shardara Reservoir and the final sampling point above the confluence with the Arys River is approximately $250 \mathrm{~km}$. Six sites were selected for repeated sampling in the river and reservoir, and three additional sites for grab samples during the growing season (Fig. 1). Site 1 , the most upstream sampling location, is immediately adjacent to the Uzbekistan border and receives inflow only during the spring and summer months. Sites 2 and $2 \mathrm{X}$ are located near reservoir inflow and outflow respectively, on the shores of the Shardara Reservoir prior to controlled release to downstream Sites 3, 4, and 5 (Fig. 1).

A suite of sampling techniques were employed to assess occurrence of pesticides in the Syr Darya. Water and sediment grab samples, along with in-situ sampling devices, including polar organic chemical integrative samplers (POCIS, Environmental Sampling Technologies, St. Joseph, MO), and continuous low-level aquatic monitoring (C.L.A.M., C.I. Agent Solutions, Louisville, KY) samplers permitted a broad range of sampling methods and sensitivity. POCIS and C.L.A.M. samplers were only used in June. Table 1 summarizes the types of samples collected during each event.

Samples from sites 1-5 were obtained in June and October 2015, though very little water was present in the river channel upstream (Site 
Table 1 Sampling regime utilized to assess the presence of pesticide residues in the Syr Darya. August samples were collected primarily to account for ephemeral irrigation canal inputs.

\begin{tabular}{|c|c|c|}
\hline Dates & Sites (Fig. 1) & Samples Types Collected \\
\hline \multirow[t]{2}{*}{ 5-6 June 2015} & $1,2,2 X, 3,4,5$ & Water and river sediment grab samples \\
\hline & $1,2 X, 5$ & POCIS, C.L.A.M. \\
\hline \multirow[t]{2}{*}{23 August 2015} & $1,2 \mathrm{X}$ & Water grab samples only \\
\hline & Irrigation ditches (6-9) & $\begin{array}{l}\text { Water grab samples only - } 4 \text { sites draining } \\
\text { into reservoir }\end{array}$ \\
\hline 12-13 October 2015 & $1,2,2 X, 3,4,5$ & Water and river sediment grab samples \\
\hline
\end{tabular}

1, Fig. 1) of the reservoir in October. In August, sites 1 and $2 \mathrm{X}$ were sampled, plus four additional grab samples of surface water from intermittently filled irrigation ditches upstream of the Shardara Reservoir (Gulistan Area and Zhetisay District) to help characterize local irrigation canal inflow water quality.

\subsection{Collection and processing of water samples}

Water samples for pesticide analysis were collected in 1-Liter square amber glass bottles and transported in a cooler filled with frozen ice packs to Al-Farabi Kazakh National University (KazNU) where they were stored at $4{ }^{\circ} \mathrm{C}$. Each 1-liter water sample was extracted within three days of collection and divided into three $300 \mathrm{~mL}$ portions by weight for solid phase extraction (SPE) and subsequent analysis by three instrumental methods. Two of these portions were spiked and equilibrated with 2000 ng terbuthylazine and butachlor surrogates to account for losses during extraction, and immediately extracted using preconditioned 1 $\mathrm{g}$ trifunctional tC18 bonded silica SPE cartridges (Waters Corporation, Milford, MA USA). The third $300 \mathrm{~mL}$ portion was extracted onto a 200 mg HLB SPE cartridge (Waters Corporation, Milford, MA USA). Reverse

phase tC18 cartridges were preconditioned onsite by passing $5 \mathrm{~mL}$ of ethyl acetate, $5 \mathrm{~mL}$ of acetonitrile, and $5 \mathrm{~mL}$ of purified (deionized distilled) reagent water, while the HLB cartridges were preconditioned using $5 \mathrm{~mL}$ acetonitrile followed by $5 \mathrm{~mL}$ of purified reagent water immediately prior to use.

During extraction, each sample portion was slowly aspirated under vacuum through $1 / 8$ " OD Teflon ${ }^{\text {TM }}$ tubing and a glass microfiber filter 
(Whatman GF/F, GF/F: $0.7 \mu$ m pore size, binderless) held in a $25 \mathrm{~mm}$ Teflon $^{\text {TM }}$ filter holder connected using a Leur adapter to each preconditioned cartridge mounted on a flow control valve and vacuum flask. The glass fiber filter was removed, and the holder rinsed with $100 \%$ ethanol and purified reagent (deionized distilled) water after each sample to minimize any cross contamination. Following extraction, each labelled SPE cartridge was air dried via vacuum aspiration at room temperature for $5 \mathrm{~min}$. and then stored in sealed zipper bags at $4{ }^{\circ} \mathrm{C}$. Processed SPE cartridges containing extracted residues were transported to the University of Nebraska Water Sciences Laboratory (UN-WSL) and stored at $-20^{\circ} \mathrm{C}$ until further processing. One of the two tC18 cartridges from each sample was utilized for the analysis of 22 nonorganochlorine pesticides, while the other was utilized for the analysis of six organochlorine pesticides. The HLB cartridges were processed for the analysis of neonicotinoids and one organophosphate insecticide.

\subsection{SPE cartridge elution}

The tC18 SPE cartridges used for non-organochlorine pesticide analysis (Table 2) were eluted with $6 \mathrm{~mL}$ of ethyl acetate, and eluate spiked with $5 \mu \mathrm{g}$ each of ${ }^{13} \mathrm{C}_{3}$-labelled atrazine, deethylatrazine (DEA) and desisopropylatrazine (DIA) added and used as internal standards. Quantitation by isotope dilution was used for atrazine, DEA and DIA and other residues were quantified using ${ }^{13} \mathrm{C}_{3}$-atrazine. Ethyl acetate extracts were evaporated under nitrogen to $\sim 1 \mathrm{~mL}$ and residual water was removed with the addition of anhydrous sodium sulfate, followed by quantitative transfer using $2 \mathrm{~mL}$ of ethyl acetate to a clean borosilicate culture tube. After vortexing, the solvent volume was then further reduced to $200 \mu \mathrm{L}$ under dry nitrogen. Concentrated extracts were transferred to autosampler vials outfitted with $300 \mu \mathrm{L}$ silane-treated glass inserts. Extracts were analyzed for the compounds listed in Table 2 by gas chromatography-mass spectrometry (GC/MS) with selected ion monitoring as described previously (Cassada et al., 1994). Further details of the analytical method and results of a validation study are provided in supplementary materials.

The second set of tC18 SPE cartridges, used for preconcentration of chlorinated pesticides, were eluted with $3 \mathrm{~mL}$ of acetone, followed by 3 $\mathrm{mL}$ of hexane, and $3 \mathrm{~mL}$ of ethyl acetate. Solvent eluate was spiked with 
Table 2 Target compounds included in analysis SPE cartridge extracts, and extracts from sediment samples, polar organic chemical integrative samplers (POCIS), continuous low-level aquatic monitoring (C.L.A.M.) samplers.

\begin{tabular}{|c|c|c|c|}
\hline \multicolumn{4}{|l|}{ tC18 cartridge 1 extracts } \\
\hline Acetochlor & Alachlor & Atrazine & Butylate \\
\hline Chlorthalonil & Cyanazine & Deethylatrazine & Deisopropylatrazine \\
\hline Dimethenamid & EPTC & Metolachlor & Metribuzin \\
\hline Norflorazon & Pendimethalin & Permethrin & Prometon \\
\hline Propachlor & Propazine & Simazine & Tefluthrin \\
\hline Terbufos & Trifluralin & & \\
\hline \multicolumn{4}{|l|}{ tC18 cartridge 2 extracts } \\
\hline 4,4-DDE & 4,4-DDT & $\alpha-\mathrm{HCH}$ & Aldrin \\
\hline$\beta-\mathrm{HCH}$ & $\partial-\mathrm{HCH}$ & Dieldrin & $\gamma$-HCH (Lindane) \\
\hline \multicolumn{4}{|l|}{ Heptachlor } \\
\hline \multicolumn{4}{|l|}{ HLB cartridge extracts } \\
\hline Acetamiprid & Clothianidin & Imidacloprid & Metalaxyl \\
\hline Dimethoate & Dinotefuran & Thiacloprid & Thiamethoxam \\
\hline \multicolumn{4}{|l|}{ Sediment } \\
\hline 4,4-DDE & 4,4-DDT & $\alpha-\mathrm{HCH}$ & Aldrin \\
\hline$\beta-\mathrm{HCH}$ & $\partial-\mathrm{HCH}$ & Dieldrin & $\gamma$-HCH (Lindane) \\
\hline \multicolumn{4}{|l|}{ Heptachlor } \\
\hline \multicolumn{4}{|l|}{ POCIS } \\
\hline Acetamiprid & Acetochlor & Atrazine & Bifenthrin \\
\hline Boscalid & Carbofuran & Chlorpyrifos & Clothianidin \\
\hline Cyhalothrin & Cyprodinil & Deltamethrin & Deethylatrazine \\
\hline Deisopropylatrazine & Diazinon & Dimethoate & Dinotefuran \\
\hline Fludioxonil & Imidacloprid & Malathion & Metalaxyl \\
\hline Methidathion & Metolachlor & Metribuzin & Parathion ethyl \\
\hline Parathion methyl & Pendimethalin & Permethrin & Pyrimethanil \\
\hline Quinoxyfen & Tebuconazole & Thiacloprid & Triadimefon \\
\hline \multicolumn{4}{|l|}{ Thiamethoxam } \\
\hline \multicolumn{4}{|l|}{ C.L.A.M. Samplers } \\
\hline Acetochlor & Atrazine & Boscalid & Carbofuran \\
\hline Chlorpyrifos & Cyprodinil & Deethylatrazine & Deisopropylatrazine \\
\hline Diazinon & Fludioxonil & Malathion & Methidathion \\
\hline Metolachlor & Metribuzan & Parathion ethyl & Parathion methyl \\
\hline Pendimethalin & Propazine & Pyrimethanil & Simazine \\
\hline
\end{tabular}

$5 \mu \mathrm{g}$ of labelled internal standards $\left({ }^{13} \mathrm{C}_{3}\right.$-atrazine, ${ }^{13} \mathrm{C}_{3}$-deethylatrazine, and ${ }^{13} \mathrm{C}_{3}$-deisopropylatrazine (Merck Sharp \& Dohme/Isotopes, St. Louis, MO USA) and slowly evaporated under dry nitrogen. Residual water was removed with anhydrous sodium sulfate during the concentration process and quantitatively transferred to clean borosilicate culture tubes using additional ethyl acetate. Each extract was evaporated completely before residues were dissolved in $200 \mu \mathrm{L}$ ethyl acetate and transferred 
to a $300 \mu \mathrm{L}$ silane-treated glass insert for analysis of chlorinated insecticides (Table 2) by full scan GC/MS. Method detection limits were determined by extraction and analysis of eight (8) replicate samples of purified reagent water fortified at $0.3 \mu \mathrm{g} / \mathrm{L}$, and range from $0.007 \mu \mathrm{g} / \mathrm{L}$ for 4-DDE to $0.053 \mu \mathrm{g} / \mathrm{L}$ for aldrin (Table S7).

Compounds retained on polymeric HLB SPE cartridges were eluted and analyzed for polar neonicotinoid and organophosphorus insecticides (Table 2) using liquid chromatography-tandem mass spectrometry (LCMS/MS). Full details of the extraction, elution and instrumental method are included in the supplemental materials. Standards for each of the target analytes, as well as isotopically labelled standards (d4-Imidacloprid, d3-Thiamethoxam and d6-Metalaxyl), were obtained from Sigma Aldrich (St. Louis, MO). Each HLB SPE cartridge was eluted under vacuum with $6 \mathrm{~mL}$ of high purity methanol (Optima, Fisher Scientific, St. Louis, MO). The eluate was spiked with $50 \mu \mathrm{L}$ of $1.0 \mathrm{ng} / \mu \mathrm{L}$ internal standard mix and evaporated under dry nitrogen in borosilicate culture tubes. The residue was dissolved in $50 \mu \mathrm{L}$ high-purity methanol and mixed with $200 \mu \mathrm{L}$ purified (distilled deionized, organic free) reagent water prior to LC-MS/ MS analysis. A well end-capped $250 \times 2 \mathrm{~mm} \times 5 \mu \mathrm{m}$ BetaBasic C18 reverse phase HPLC column (ThermoFisher, St. Louis, MO USA) was used for the gradient separation with $0.15 \%$ formic acid in methanol/water (97:3) and $0.15 \%$ formic acid in water/methanol (97:3) at a constant temperature of $50{ }^{\circ} \mathrm{C}$ and a flow rate of $0.3 \mathrm{~mL} / \mathrm{min}$. Analysis run time was $30 \mathrm{~min}$, with positive ion mode atmospheric pressure chemical ionization (APCI) on a Waters Quattro Micro triple quadrupole mass spectrometer (Waters Corporation, Milford, MA USA). A pseudo-molecular ion $[\mathrm{M}+\mathrm{H}]^{+}$for each compound was selected as the parent ion for fragmentation, and corresponding fragment ion(s) selected for identification and quantitation (Table S7).

Compound recovery and method detection limits, determined through 8 to 10 replicate analyses of low-level fortified blanks (USEPA, 1986), are presented in Table S10. Method detection limits ranged from 0.005 to $0.025 \mu \mathrm{g} / \mathrm{L}$. Quality controls processed in Kazakhstan included laboratory duplicates and method blanks prepared from distilled deionized water. Additional quality controls processed in the U.S. were laboratory fortified blank and method blanks. Results of quality controls, together with analysis of certified reference material samples, are included in the supplemental section. 


\subsection{Collection and chemical analysis of sediment grab samples}

Sediment samples ( $\sim 200 \mathrm{~g}$ ) were collected in $250 \mathrm{~mL}$ amber jars, held on ice and then transferred to a freezer for subsequent extraction using microwave assisted solvent extraction with analysis by GC/MS. Briefly, 5 grams of wet sample was weighed into a $10 \mathrm{~mL}$ Teflon $^{\mathrm{TM}}$ microwave digestion vessel, spiked with 200 ng surrogate compounds, and thoroughly mixed with $6 \mathrm{~mL}$ of acetonitrile. Batches of up to 40 samples were then subjected to microwave irradiation (400W) for $10 \mathrm{~min}$ at $90{ }^{\circ} \mathrm{C}$ using a MARS Xpress microwave digestion system (CEM, Matthews, NC USA). After cooling and decanting the solvent, sediment was mixed with an additional $6 \mathrm{~mL}$ of acetonitrile, allowed to settle and the clear solvent combined with the first portion. Extract volume was then reduced to near 1-2 mL under dry nitrogen and spiked with $500 \mathrm{ng}$ of isotope-labelled internal standards. The acetonitrile was mixed with $100 \mathrm{~mL}$ of water, and extracts were purified by reverse phase (tC18) solid phase extraction (SPE) cartridges used in water extraction. Absorbed compounds were then eluted with ethyl acetate and analyzed by GC/MS as described above. Method detection limits, determined from extraction and analysis of eight replicates of $5 \mathrm{~g}$ of clean sand spiked at $4.0 \mathrm{ng} / \mathrm{g}$, ranged from $0.4 \mathrm{ng} / \mathrm{g}$ for trifluralin to $5.0 \mathrm{ng} / \mathrm{g}$ for dieldrin (Table S5).

\subsection{Deployment, calibration and chemical analysis of POCIS}

Polar organic chemical integrative samplers (POCIS) are an effective method for passive sampling of polar organic compounds at a variety of spatial and temporal scales, though estimation of concentrations re-

quire use of compound-specific uptake rates. For this project sampling rates for target compounds were determined in the laboratory. Nine POCIS were obtained from Environmental Sampling Technologies (St. Joseph, MO USA), placed in three stainless-steel deployment canisters, and deployed at three of the sampling sites for seven days during the June sampling campaign. One POCIS canister, deployed at location 2X (Fig. 1 ), was missing and presumed lost at the conclusion of deployment. Upon retrieval, each POCIS deployment canister was placed in a plastic bag and put in a cooler containing ice packs until transport to the laboratory at Al-Farabi KazNU. Within three days of retrieval, the HLB sorbent from each POCIS was removed and quantitatively transferred to 
glass chromatography columns containing a plug of glass wool by gently rinsing the polymer with purified deionized water. After draining the water, three $20 \mathrm{~mL}$ portions of reagent grade acetonitrile were used to slowly extract and elute compounds from the sorbent. The POCIS extracts were evaporated under dry nitrogen to $\sim 30 \mathrm{~mL}$, stored in glass vials with Teflon ${ }^{\mathrm{TM}}$-lined caps and transported to the Water Sciences Laboratory, University of Nebraska, USA for elution and analysis of pesticide residues. After spiking the extract with internal standards listed in the method for water samples, the extracts were evaporated to dryness, spiked with $50 \mu \mathrm{L}$ of $1.0 \mathrm{ng} / \mu \mathrm{L}$ internal standard mix, and completely evaporated under dry nitrogen in borosilicate culture tubes. The residue was dissolved in $50 \mu \mathrm{L}$ high purity methanol and mixed with $200 \mu \mathrm{L} \mathrm{pu}-$ rified (distilled deionized, organic free) reagent water and analyzed for neonicotinoid and organophosphate insecticides (Table 2).

Uptake rates for the neonicotinoids and dimethoate using POCIS were determined in the laboratory using procedures detailed previously (Bartelt-Hunt et al., 2011). Briefly, three POCIS were suspended in stirred 2-Liter aqueous solutions spiked with $5 \mu \mathrm{g} / \mathrm{L}$ of all compounds in $\mathrm{pH}$ = 7.0 buffered reagent water. A fourth stirred solution (without POCIS) was stirred and used a control. Fifty milliliter portions of each solution were removed at the beginning of the uptake experiment and after 1 day, 3 days, 7 days, and 14 days of exposure to the POCIS device. The aqueous concentration was measured in each solution and the observed decrease in the aqueous concentration of neonicotinoids over time was modeled by using first-order kinetics based on the following equation:

$$
C_{w}(t)=C_{w}(0) \exp [-k t]
$$

where $C_{w}(t)$ is the aqueous concentration at time $t ; C_{w}(0)$ is the aqueous concentration at time 0 ; and $\mathrm{k}$ is the rate constant. The value of $\mathrm{k}$ was determined from the natural logarithm of the slope of the change in water concentration over the exposure time. The POCIS uptake rate $\left(\mathrm{R}_{\mathrm{s}}\right)$ was calculated as:

$$
\mathrm{R}_{\mathrm{s}}=\mathrm{k}_{\mathrm{U}} \mathrm{V}_{\mathrm{T}}
$$

where $V_{T}$ was the total volume of the water in the container. Volume changes in the beakers due to sampling during the sampling events were 
considered by adjusting the values of $\mathrm{V}_{\mathrm{T}}$. Uptake rates were calculated using all data created over the 14 days exposure (Table S9).

\subsection{Use and processing of continuous low-level aquatic monitoring (C.L.A.M.) samplers}

The C.L.A.M. sampler devices were outfitted with HLB-H Disks (\#A50HLB-H) and used as described by the manufacturer (C.I. Agent StormWater Solutions, Louisville, KY USA). Total sample volumes at each location were calculated by estimating total flow through the C.L.A.M. over the extraction period per manufacturer recommendation. The C.L.A.M. (\#HLB-H Disk A50-HLB-H) samplers were processed for the analytes listed in Table 2. Elution followed modified manufacturer protocols by slowly passing $50 \mathrm{~mL}$ of methanol through the disk followed by $50 \mathrm{~mL}$ of methylene chloride directly into a 150 mL RapidVap N2 glass vial (Labconco Corp, Kansas City, MO USA). The resultant mixture was spiked with 5000 ng each of ${ }^{13} \mathrm{C}_{3}$-atrazine, ${ }^{13} \mathrm{C}_{3}$-deethylatrazine (DEA) and ${ }^{13} \mathrm{C}_{3}$ deisopropylatrazine (DIA), and $2000 \mathrm{ng}$ of terbuthylazine and butachlor surrogates, and then evaporated completely at $40{ }^{\circ} \mathrm{C}$ under nitrogen. The concentrated residue was dissolved in hexane, transferred to 300 $\mu \mathrm{L}$ silane-treated glass insert for analysis of pesticides by full scan GC/ MS (Cassada et al., 1994). Instrumental conditions are the same as those listed for herbicide and organophosphorus insecticides determined in grab samples.

\subsection{Risk assessment}

A preliminary ecotoxicological risk assessment for DDT and $\gamma-\mathrm{HCH}$ concentrations in river water samples was conducted via calculation of hazard quotients (HQ) using equation (3), based on USEPA guidelines (USEPA, 1998):

$$
\mathrm{HQ}=\frac{\mathrm{MEC}}{\mathrm{PNEC}}
$$

where MEC = maximum reported environmental concentration, and PNEC = predicted no-effect concentration. The PNEC values were obtained from previously published methods (Chakraborty et al., 2016; 
Chen et al., 2020; Zeng et al., 2018) for five species in five groups in different trophic levels - zooplankton, phytoplankton, mollusk, insects, and fishes. HQs were determined for each sampling site to characterize risk throughout this stretch of river.

Potential risk from organochlorine pesticide exposure in sediments was evaluated by comparing the mean concentrations of detected pesticides in the sediment with the threshold effect level (TEL) and probable effect level (PEL) given by the Canadian Council of Ministry of the Environment Guidelines (CCME, 2006) and effect range of low (ERL) level mentioned in other studies (Long et al., 1998; Yang et al., 2013). Potential toxicity in the mixture was estimated in terms of sediment quality guideline quotient (SQGQ) reported in several papers (Long and MacDonald, 1998; Wang et al., 2017).

$$
\mathrm{SQGQ}=\sum_{x=1}^{n} \frac{P E L Q_{X}}{n}
$$

where,

$$
P E L Q_{x}=\frac{C_{x}}{P E L}
$$

where, $P E L$ is the guideline value for contaminant " $\mathrm{x}$ ", $C_{x}$ is the measured concentration of the same contaminant, and " $n$ " is the number of contaminants for which sediment guidelines are available. SQGQ values < 0.1 indicates no effects; $0.1 \leq \mathrm{SQGQ}<1$ indicates moderate effects and SQGQ $\geq 1$, high adverse biological effects (Costa et al., 2011).

\section{Results and discussion}

A summary of pesticide residues detected is presented in Table 3. Even with the large number of target compounds measured, the number of detections and relative concentrations is remarkably low given the agriculturally-intensive history of this region. Residues of current-use and legacy chlorinated pesticides were detected in grab samples, bottom sediment and passive sampling devices. The highest concentrations were found among legacy pesticide residues in both the water column and sediment samples. Monthly recorded precipitation was highest Zhetysay, KZ located $10 \mathrm{~km}$ south of Shardara reservoir (Fig. 1) in May 24 
Table 3 Detected pesticide concentrations measured from the Syr Darya sampling sites. POCIS concentrations represent time-weighted average concentration determined from the mass ( \pm standard deviation) of three POCIS deployed at each site. "ND" = "Not Detected" "-" = "Not Sampled".

\begin{tabular}{|c|c|c|c|c|c|c|c|c|c|c|c|}
\hline Pesticide & Month & Site 1 & Site 2 & Site $2 X$ & Site 3 & Site 4 & Site 5 & Site 6 & Site 7 & Site 8 & Site 9 \\
\hline \multicolumn{12}{|c|}{ Grab Samples444 - Water (mg/L) } \\
\hline \multirow[t]{2}{*}{ Lindane } & June & 0.16 & 0.17 & 0.24 & 0.18 & 0.21 & 0.17 & - & - & - & - \\
\hline & Aug & 0.09 & ND & ND & - & - & - & 0.15 & 0.06 & 0.12 & \\
\hline \multicolumn{12}{|l|}{0.13} \\
\hline \multirow{4}{*}{ Dieldrin } & Oct & 0.18 & 0.10 & 0.014 & 0.09 & 0.06 & 0.08 & - & - & - & - \\
\hline & June & ND & ND & ND & ND & ND & ND & - & - & - & - \\
\hline & Aug & ND & ND & 0.07 & - & - & - & 0.19 & ND & 0.02 & 015 \\
\hline & Oct & 0.14 & 0.27 & ND & 0.37 & ND & 0.23 & - & - & - & - \\
\hline \multirow[t]{3}{*}{ Aldrin } & June & ND & ND & ND & ND & ND & ND & - & - & - & - \\
\hline & Aug & ND & ND & ND & - & ND- & - & ND & ND & ND & ND \\
\hline & Oct & ND & ND & 0.10 & ND & ND & ND & - & - & - & - \\
\hline \multirow[t]{3}{*}{ Imidacloprid } & June & ND & ND & ND & ND & ND & ND & - & - & - & - \\
\hline & Aug & ND & ND & 0.008 & - & - & - & ND & ND & ND & ND \\
\hline & Oct & 0.013 & ND & ND & ND & ND & ND & - & - & - & - \\
\hline \multirow[t]{3}{*}{ Dimethoate } & June & ND & ND & ND & ND & ND & ND & - & - & - & - \\
\hline & Aug 2015 & ND & ND & ND & - & - & - & ND & ND & ND & ND \\
\hline & Oct 2015 & ND & ND & ND & ND & ND & ND & - & - & - & - \\
\hline \multicolumn{12}{|c|}{ Grab Samples -Bottom Sediment (ng/g) } \\
\hline \multirow[t]{2}{*}{$p, p^{\prime}-\mathrm{DDE}$} & June 2015 & 2.45 & ND & ND & 0.52 & ND & ND & & & & \\
\hline & Oct 2015 & 1.49 & ND & 0.19 & 0.18 & ND & ND & & & & \\
\hline \multirow[t]{2}{*}{ Trifluralin } & June 2015 & 0.20 & 0.14 & ND & ND & ND & ND & & & & \\
\hline & Oct 2015 & ND & ND & ND & ND & ND & ND & & & & \\
\hline \multicolumn{12}{|c|}{ POCIS - time-weighted average concentrations (ng/L) } \\
\hline Atrazine & June 2015 & $1.11 \pm 0.7$ & & & & & $1.19 \pm 0.8$ & & & & \\
\hline Acetamiprid & June 2015 & $0.18 \pm 0.1$ & & & & & ND & & & & \\
\hline Dimethoate & June 2015 & $0.74 \pm 0.1$ & & & & & $0.36 \pm 0.1$ & & & & \\
\hline Imidacloprid & June 2015 & $1.15 \pm 0.1$ & & & & & ND & & & & \\
\hline Metolachlor & June 2015 & $0.476(\mathrm{~J})$ & & & & & $0.722 \pm 0.5$ & & & & \\
\hline
\end{tabular}

$\mathrm{mm}$ and dropped to $1 \mathrm{~mm}$ or less for June through October. Discharge at Site 1 was highest in May and averaged $167 \mathrm{~m}^{3} / \mathrm{s}$ during this period (Supplemental Information). Based on recorded precipitation and discharge measurements, June samples should correspond periods when instream concentrations are from precipitation triggered run-off, while August and October samples would be more characteristic of irrigation water-supplied pesticides (Fig. S1).

\subsection{Legacy pollutants in the Syr Darya}

Lindane was detected in nearly all of the surface water grab samples at concentrations ranging from $0.014 \mu \mathrm{g} / \mathrm{L}$ to $0.24 \mu \mathrm{g} / \mathrm{L}$. The average 
$( \pm$ SD) lindane concentration across all sampling dates was $0.130 \pm 0.06$ $\mu \mathrm{g} / \mathrm{L}$ and the highest concentrations were measured in the June samples (Table 3). The organochloride insecticide aldrin and its metabolite dieldrin were detected in grab samples collected in August and October at concentrations up to $0.37 \mu \mathrm{g} / \mathrm{L}$. Sediment samples contained residues of $p, p^{\prime}$-DDE at concentrations ranging from 0.18 to $2.45 \mathrm{ng} / \mathrm{g}$ upstream and downstream (Sites 2 and $2 \mathrm{X}$ ) of the Shardara Reservoir, and trifluralin at $0.20 \mathrm{ng} / \mathrm{g}$ upstream of the reservoir (Site 1 ) and at $0.14 \mathrm{ng} / \mathrm{g}$ in the reservoir grab sample (Site 2), both collected in June (Table 3). Other chlorinated pesticides, including heptachlor and p,p'-DDT, as well as the hexachlorohexane isomers $(\alpha-\mathrm{HCH}$ and $\beta-\mathrm{HCH})$ typically found as manufacturing impurities were not detected in any grab samples.

\subsection{Current-use neonicotinoid and organophosphorus pesticides}

Imidacloprid was detected in the upstream grab samples at sites 1 and $2 \mathrm{X}$ in October and August, respectively, while dimethoate was detected at site 1 in October (Table 3 ). These insecticides are comparatively polar and mobile with relatively short half-lives, suggesting that they were used in close proximity (temporally and spatially) to the sites where they were detected.

\subsection{Residues in POCIS and C.L.A.M. Sampler extracts}

The C.L.A.M. samplers used in the June sampling contained trace levels $(\sim 0.05 \mu \mathrm{g} / \mathrm{L})$ of atrazine at Site 1 and cyprodinil at Site 2 , but all other compounds were below detection limits. The absence of residue detections was potentially due to variability in volume of water extracted at each location, ranging from $\sim 0.5$ to $3.8 \mathrm{~L}$ primarily due to the high levels of suspended solids. The volume extracted is estimated based on the field-measured flowrate and time elapsed between sampler submersion and removal and this flow rate varies considerably depending on the battery condition and time until the extraction disk filter frit became plugged. Differences in concentrations and frequency of detections between C.L.A.M. sampler and other devices or grab samples has been previously reported (Coes et al., 2014; Ensminger et al., 2017). Generally, frequency of detection is reported to be higher than those measured from grab samples but concentrations may be lower. The C.L.A.M. 
sampler may be very effective for surface water with low levels of suspended solid but likely has limited application in turbid river water.

Of $\sim 33$ pesticide residues monitored, POCIS extracts contained detectable levels of two neonicotinoid insecticides (acetamiprid and imidacloprid), an organophosphorous insecticide (dimethoate), atrazine and metolachlor at Site 1 (Table 3). Three of these compounds (atrazine, dimethoate and metolachlor) were also detected at Site 5 in June. POCIS have been extensively used to quantify the levels of polar organic pollutants like pharmaceuticals, pesticides, and hormones in water as reported elsewhere (Alvarez et al., 2007; Arditsoglou and Voutsa, 2008; MacLeod et al., 2007; Sellin et al., 2009).

Passive sampling provides low detection limits and ability to integrate over long sampling times which is good incentive for their use in toxicological studies (Alvarez et al., 2008; Kolok et al., 2014; Sellin et al., 2009). The results of the POCIS uptake rate experiments, provided in the supplemental materials (Table S9), were used to convert pesticide mass recovered to time weighted average concentrations during the 7-day exposure period in June 2015 (Table 3). Sampling uptake rates for neonicotinoids were found to vary between 0.24 and $0.76 \mathrm{~L} /$ day excluding dinotefuran, which showed almost negligible uptake to the POCIS. Low uptake for this compound is likely due to the fact that this compound is a weak base $(\mathrm{pKa}=12.6)$ and high water solubility $(54,300$ $\mathrm{mg} / \mathrm{L})$. Linear rates of uptake rates $\left(\mathrm{r}^{2}\right.$ between 0.6 and 0.9$)$, observed for acetamiprid, chothianidin, imidacloprid, metalaxyl, thiacloprid and thiamethoxam (Table S9), permitted estimation of average concentrations in the river where residues were detected in POCIS. Estimated time weighted average (TWA) concentrations were below $0.005 \mu \mathrm{g} / \mathrm{L}$. Higher TWA levels were measured in the POCIS deployed upstream from the Shardara Reservoir (Fig. 1). None of the herbicides, pyrethroids, traditional organophosphorous insecticides, or fungicides were detected in the grab samples.

\subsection{Occurrence and potential sources of legacy pesticides}

Lindane was detected in the water column but was not measurable in sediment samples, suggesting that this pesticide may have entered the water upstream via irrigation return flow. Over $80 \%$ of the total land area upstream of the Shardara Reservoir is located in the Ferghana 
Valley of Uzbekistan and is devoted to intensive cotton agriculture. It has been reported that banned pesticides may continue to be used in these remote intensively agricultural areas (Wegerich et al., 2015). Estimated flux at Site 1 near the border between Uzbekistan and Kazakhstan of lindane is similar in June and October 2015, while dieldrin and imidacloprid is higher in October (Table S10). The concentrations of lindane and dimethoate in the water column are remarkably similar to those reported in the 1990s (Chernogaeva et al., 1998) and the chronic occurrence of lindane is a concern for both aquatic organisms and human health, particularly given that lindane has been classified as a Group I carcinogen (Loomis et al., 2015). Food crops such as potatoes and melons are produced in irrigated fields downstream of the Shardara Reservoir and presumably use water diverted from the Syr Darya (Fig. 1). Occurrence of legacy pesticides in irrigation water may also affect food quality, as a recent study of pesticide residues in crops from northern Kazakhstan reported detectable levels of pesticides including DDT, $\gamma-\mathrm{HCH}$, aldrin, and diazinon (Lozowicka et al., 2014).

The ranges of lindane concentrations in samples from the Syr Darya are comparable to those previously reported in other agriculturally-contaminated rivers around the world (Table 4). Mean lindane concentration in Syr Darya is among the highest reported for rivers of China, Pakistan, India, and Africa (Table 4). Comparable $\gamma$-HCH concentrations have been reported in the Kucuk Menderes River in Turkey (Turgut, 2003) and the Yamuna (Kumar et al., 2012) and Brahmaputra (Chakraborty et al., 2016) in India. Banned organochlorine pesticide residues have also been reported in surface water from a national park in Turkey (Turgut et al., 2010). The elevated concentrations in the Syr Darya suggests that despite the ban on legacy POPs some of these organochlorine pesticides may continue to occur in the riverine environment of Kazakhstan. Recent reviews suggests that residues of these persistent organochlorine pesticides are widespread throughout Asia (Ali et al., 2014) and there is also growing evidence for continued use of banned pesticides as well as atmospheric recirculation throughout areas of high use in the south Asian riverine environment (Chakraborty et al., 2016). In addition to replenishment from irrigation return flow from fields with previously contaminated soils, a possible mechanism for delivering these compounds in the Syr Darya could be from long range atmospheric recirculation and deposition (Ali et al., 2014). 
Table 4 Reported lindane concentrations in river samples from in Asia and Africa.

\begin{tabular}{lllll} 
River & Country & Range $(\mu g / L)$ & Mean $(\mu g / L)$ & Reference \\
\hline Syr Darya & Kazakhstan & $0.014-0.240$ & 0.187 & This study \\
Chenab & Pakistan & $0.0011-0.08$ & 0.025 & Eqani et al. (2012) \\
Kucuk Menderes & Turkey & ND-0.398 & 0.198 & Turgut (2003) \\
Huihe & China & $0.0002-0.00377$ & 0.002 & Feng et al. (2011) \\
Beijing & China & $0.0002-0.00371$ & 0.007 & Jiawei et al. (2008) \\
Niger & Africa & $0.015-0.0468$ & 0.029 & Unyimadu et al. (2017) \\
Gomti & India & ND-0.0634 & 0.008 & Malik et al. (2009) \\
Yamuna & India & $0.0001-0.165$ & 0.120 & Kumar et al. (2012) \\
Ghaggar & India & ND-0.0487 & 0.005 & Kaushik et al. (2008) \\
Hooghly & India & $0.003-0.5$ & 0.123 & Khuman and Chakraborty (2019) \\
Brahmaputra & India & ND-0.014 & 0.006 & Chakraborty et al. (2016) \\
\hline
\end{tabular}

Snowmelt has been found to contain substantial quantities of lindane in the Russian Arctic and is thought to contribute substantially to dissolved pesticide loading in these nonagricultural regions (Hoferkamp et al., 2010). As in other areas of Central and southern Asia (Ali et al., 2014), snow accumulation in the Tian Shen mountains facilitates deposition of a wide variety of semi-volatile organochlorine chemicals in this region including $\gamma$-HCH. Significant concentrations of these chemicals are often released from melting snowpack (Meyer et al., 2011) and concentrations have been previously reported to peak during snowmelt in late spring, as observed in this study. Similarly, measurable concentrations of both legacy and current-use pesticides have also been reported in snowmelt from the western U.S. (Hageman et al., 2006). It seems increasingly apparent that studies of residual contamination of surface water must consider atmospheric deposition as potential source. Repeated detection of dieldrin in the Syr Darya water column in October is consistent with its greater persistence in soils compared to aldrin (Chakraborty et al., 2016) and likely attributed to inputs from irrigation return flows.

\subsection{From chemical concentration to risk assessment}

The relative risk for aquatic organisms can be estimated from the detected chemical concentrations using the hazard quotient (equation (3)), or "HQ" discussed previously. Using literature values, it is likely that phytoplankton and zooplankton are at a higher risk from measured concentrations of lindane and DDT (Fig. 2) than are other organisms, including 


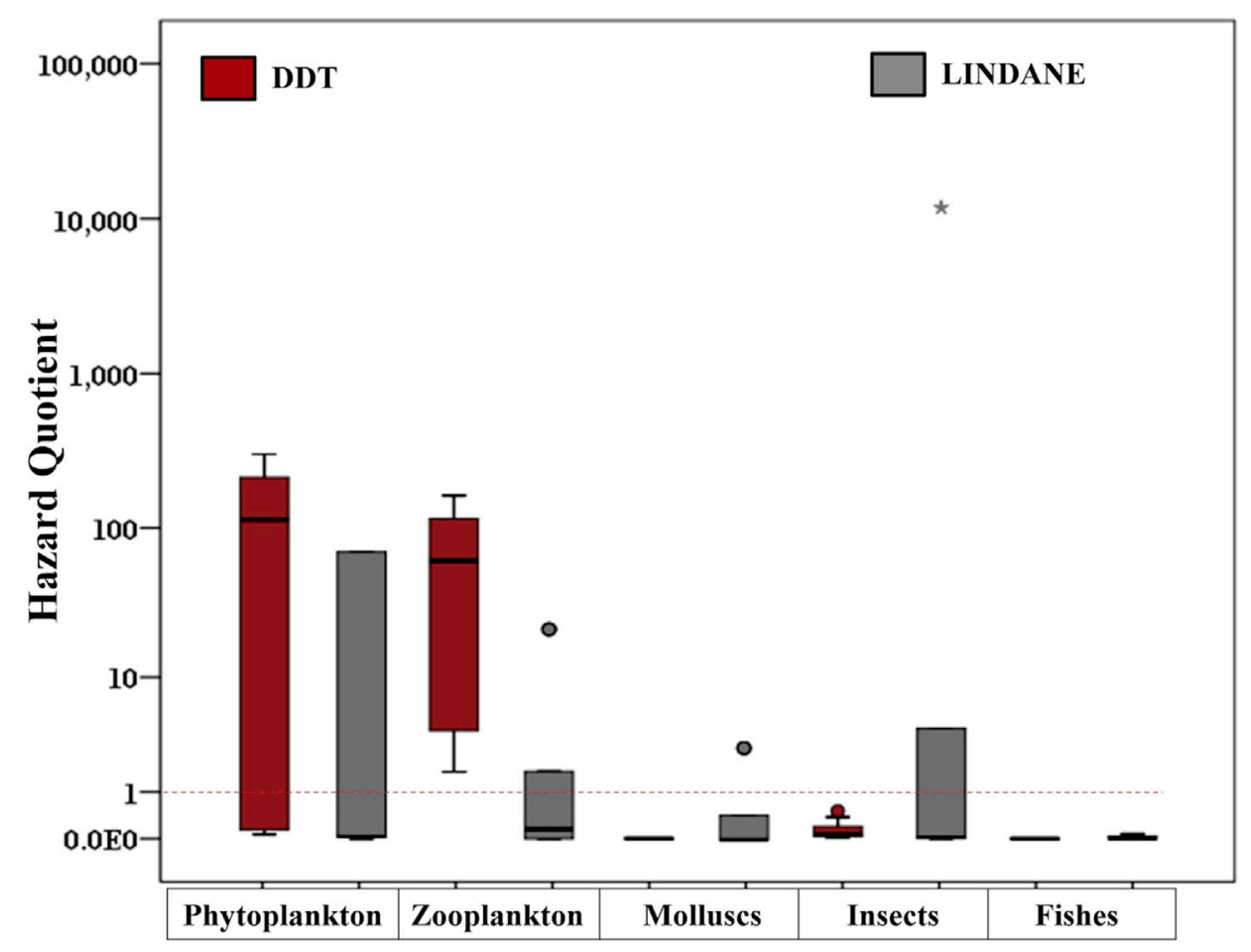

Fig. 2. Box and whisker plot showing the ranges of Hazard Quotient values based on measured DDT and lindane concentrations in the Syr Darya.

fish and other vertebrates. This observation is consistent with the reports from the lower stretch of Ganga (Khuman and Chakraborty, 2019) and Brahmaputra (Chakraborty et al., 2016) rivers in India and in Pakistan (Ali et al., 2014) in south Asia where these organochlorine pesticides have been extensively used not only for agricultural purposes and disease vector control. Similarly, central Asia has a history of heavy usage of these pesticides leading to accumulations in upstream soils and glacier snowmelt that feed the Syr Darya.

Most measured pesticide concentrations were below the detection limits in sediment samples, and this observation is surprising considering that the legacy chlorinated pesticides are hydrophobic. However, the occurrence of measurable concentrations of $p, p^{\prime}$-DDE in samples collected from Site 1 during June and October, might pose some risk to the ambient biota. SQGQ ranged between 0.1 and 1 for Site 1 during June and October 2016, indicating moderate biological effects. At 2X, the SQGQ value during October is less than 0.1. At Site 3 , the June SQGQ values were between 0.1 and 1 indicating moderate biological effects but during October month, the SQGQ was less than 0.1 indicating no effects. 


\subsection{Regulatory framework-POPs convention in Central Asia}

The collapse of the former Soviet Union in 1991 led to widespread abandonment of agricultural land use and crop production in Central Asia. In some areas of northern Kazakhstan, for example almost $45 \%$ of the intensive cropland reverted to grassland by the year 2001 (Kraemer et al., 2015). Since then, cropland area is slowly increasing throughout much of Central Asia mostly in previously intensive regions like the Syr Darya basin. According to the Food and Agriculture Organization statistics, pesticide use in Asia has almost doubled since 1992 and averaged between 3.5 and $4.0 \mathrm{~kg} / \mathrm{ha}$ of cropland as of 2014 (World Health Organization, 2020). Asia and the Americas lead the world in global use of pesticides for crop production. Pesticide use in some regions of Central Asia may still include application of persistent organic pollutants (POPs) banned under the Stockholm Convention. Stockpiles, and potentially illegally manufactured pesticide have undoubtedly been used in many parts of Central Asia and some use may continue to be as long as supplies exist or are maintained (Ali et al., 2014; Chakraborty et al., 2016).

During an inventory of obsolete pesticides carried out in 2001 (prior to Kazakhstan signing the Stockholm Convention), the country estimated that it had on hand approximately 621 tons of unusable products. Currently, pesticide stockpiles and waste materials from manufacturing may be stored unsecured in many remote areas. In the 1990s the government of Kazakhstan has banned the sale of many pesticides including lindane and DDT (Kraemer et al., 2015). Accumulated stockpiles of POPs in the Republic of Kazakhstan at the time of the report were estimated at 15.5 tons, including $\sim 0.5$ tons of DDT (East Kazakhstan oblast). In 2002, 105 tons of unwanted pesticides were disposed (buried) in the East Kazakhstan oblast (Kazakhstan, 2009), including 0.5 tons of DDT. Mixtures of pesticides of unknown composition constitute $72.0 \%$ of the total number. $\mathrm{HCH}$ isomers and lindane were reportedly not manufactured in Kazakhstan, but likely included among imported pesticides and stockpiles. According to the Ministry of Agriculture, $\mathrm{HCH}$ was not used in the territory of Kazakhstan, however a recent study reported high concentrations of organochlorine pesticides, including residues of DDT and $\mathrm{HCH}$, in soils around a former storage facility in eastern Kazakhstan (Sailaukhanuly et al., 2016). These results suggest at the very least that lindane has been used or accumulated in soils upstream. Regular monitoring of POPs is 
not conducted in Kazakhstan or Uzbekistan and upstream use or runoff of previous use may impact water quality across its border. A lack of resources will likely inhibit the monitoring of POPs in the environment as well improving our understanding of the impact of POPs on the local environment and the health of the local residents.

\section{Conclusions}

The Aral Sea remains one of the most noteworthy hydrological and ecological case studies in the world, yet little has been published about its current condition and future prospects. Passive and grab sampling can help provide a snapshot of modern and legacy pesticide residue concentrations and risks to aquatic organisms in remote watersheds such as the Syr Darya. This study provides some insight into the occurrence and concentrations of pesticides in the Syr Darya. Low concentrations of legacy pesticides, such as lindane and DDT residues occur and could be the result of upstream use but could also be from recycled legacy contamination either through atmospheric deposition or runoff via current irrigation practices. Low concentrations of modern pesticides, such as imidacloprid, also occur early in the irrigation season and may affect suitability of river water for other purposes.

This work illustrates the possibilities and difficulties of working in remote environments, and while environmental contamination can be readily assessed by analyzing grab and integrated samples, the toxicological impacts of those chemicals may be difficult to ascertain. Many indices that may better convey the significance of concentration measurements, such as the HQ, incorrectly imply that it is relatively simple to assess toxicity across trophic levels. The robustness of those estimates, as well as the associated risk assessment, are in question and still remain to be empirically demonstrated. Future studies of current surface water quality, and the toxicological impacts of chemicals from past and present agriculture in this region are needed to ensure long term sustainable development. Finally, contamination from past and present use of banned pesticides should be considered in any ecotoxicological assessment of this region. 
Competing interest The authors declare that they have no known competing financial interests or personal relationships that could have appeared to influence the work reported in this paper.

Acknowledgments This study was funded through a National Science Foundation's Catalyzing New International Collaborations (CNIC) Program grant (\#1427834) awarded to D. Snow., A. Kolok, S. Bartelt-Hunt and M.K. Jeffries. Additional funding was provided through a Kazakhstan Ministry of Education and Science grant (\#1547/ GF4) to B. Uralbekov. Thanks to Emily Shafto, Maria Rakestraw, Nurbek Nurpesov, Zhandos Shalabayev and Ilona Matveyeva for assistance in sample collection and processing in Kazakhstan.

Appendix A. Supplementary data Supplementary data to this article follows the References.

\section{References}

Ali, U., Syed, J.H., Malik, R.N., Katsoyiannis, A., Li, J., Zhang, G., Jones, K.C., 2014. Organochlorine pesticides (OCPs) in South Asian region: a review. Sci. Total Environ. 476-477, 705-717.

Alvarez, D.A., Cranor, W.L., Perkins, S.D., Clark, R.C., Smith, S.B., 2008. Chemical and toxicologic assessment of organic contaminants in surface water using passive samplers. J. Environ. Qual. 37 (3), 1024-1033.

Alvarez, D.A., Huckins, J.N., Petty, J.D., Jones-Lepp, T., Stuer-Laridsen, F., Getting, D.T., Goddard, J.P., Gravell, A., 2007. Tool for monitoring hydrophilic contaminants in water: polar organic chemical integrative sampler (POCIS). In: Greenwood, R., Mills, G., Vrana, B. (Eds.), Comprehensive Analytical Chemistry. Elsevier, pp. 171-197.

Arditsoglou, A., Voutsa, D., 2008. Passive sampling of selected endocrine disrupting compounds using polar organic chemical integrative samplers. Environ. Pollut. 156 (2), 316-324.

Bartelt-Hunt, S.L., Snow, D.D., Damon-Powell, T., Brown, D.L., Prasai, G., Schwarz, M., Kolok, A.S., 2011. Quantitative evaluation of laboratory uptake rates for pesticides, pharmaceuticals, and steroid hormones using POCIS. Environ. Toxicol. Chem. 30 (6), 1412-1420.

Cai, X., McKinney, D.C., Lasdon, L.S., 2002. A framework for sustainability analysis in water resources management and application to the Syr Darya Basin. Water Resour. Res. 38 (6), 21-1-21-14.

Cassada, D.A., Spalding, R.F., Cai, Z., Gross, M.L., 1994. Determination of atrazine, deethylatrazine and deisopropylatrazine in water and sediment by isotope dilution gas chromatography-mass spectrometry. Anal. Chim. Acta 287, 7-15.

CCME, 2006. Canadian Council of ministers of the environment. Canadian water quality guidelines for the protection of aquatic life published by health Canada on behalf of the federal-provincial-territorial committee on drinking water (CDW). http://www.ccme.ca/ verified 26 May 2020. 
Chakraborty, P., Khuman, S.N., Selvaraj, S., Sampath, S., Devi, N.L., Bang, J.J., Katsoyiannis, A., 2016. Polychlorinated biphenyls and organochlorine pesticides in River Brahmaputra from the outer Himalayan Range and River Hooghly emptying into the Bay of Bengal: Occurrence, sources and ecotoxicological risk assessment. Environ. Pollut. 219, 998-1006.

Chen, C., Zou, W., Chen, S., Zhang, K., Ma, L., 2020. Ecological and health risk assessment of organochlorine pesticides in an urbanized river network of Shanghai, China. Environ. Sci. Eur. 32 (1), 1-14.

Chernogaeva, G.M., Lvov, A.P., Georgievsky, V.Y., 1998. Water Use and Influene of Anthropogenic Activity. In: Kimstach, V, Meybeck, M, Baroudy, E. (Eds.), A Water Quality Assessment of the Former Soviet Union. E \& FN Spoon, London and New York, pp. 69-94.

Coes, A.L., Paretti, N.V., Foreman, W.T., Iverson, J.L., Alvarez, D.A., 2014. Sampling trace organic compounds in water: a comparison of a continuous active sampler to continuous passive and discrete sampling methods. Sci. Total Environ. 473, 731-741.

Costa, P.M., Neuparth, T.S., Caeiro, S., Lobo, J., Martins, M., Ferreira, A.M., Caetano, M., Vale, C., DelValls, T.A., Costa, M.H., 2011. Assessment of the genotoxic potential of contaminated estuarine sediments in fish peripheral blood: laboratory versus in situ studies. Environ. Res. 111 (1), 25-36.

Ensminger, M.P., Vasquez, M., Tsai, H.-J., Mohammed, S., Van Scoy, A., Goodell, K., Cho, G., Goh, K.S., 2017. Continuous low-level aquatic monitoring (CLAM) samplers for pesticide contaminant screening in urban runoff: analytical approach and a field test case. Chemosphere 184, 1028-1035.

Eqani, S.A.-M.-A.-S., Malik, R.N., Katsoyiannis, A., Zhang, G., Chakraborty, P., Mohammad, A., Jones, K.C., 2012. Distribution and risk assessment of organochlorine contaminants in surface water from River Chenab, Pakistan. J. Environ. Monit. 14 (6), 1645-1654.

Feng, J., Zhai, M., Liu, Q., Sun, J., Guo, J., 2011. Residues of organochlorine pesticides (OCPs) in upper reach of the Huaihe River, East China. Ecotoxicol. Environ. Saf. 74 (8), 2252-2259.

Frenken, K., 2013. Irrigation in central Asia in figures - AQUASTAT survey 2012. FAO reports 39, food and agriculture organization of the United Nations. http://www. fao.org (Accessed 26 May 2020). Rome, Italy.

Glantz, M.H., 2007. Aral Sea basin: a Sea dies, a Sea also rises. AMBIO A J. Hum. Environ. 36 (4), 323-327, 325.

Hageman, K.J., Simonich, S.L., Campbell, D.H., Wilson, G.R., Landers, D.H., 2006. Atmospheric deposition of current-use and historic-use pesticides in snow at national parks in the western United States. Environ. Sci. Technol. 40 (10), 3174-3180.

Hecht, J., 2014. Arid Aral Sea could be resurrected. New Scientist 222 (2971), 16.

Hoferkamp, L., Hermanson, M.H., Muir, D.C.G., 2010. Current use pesticides in Arctic media: 2000-2007. Sci. Total Environ. 408 (15), 2985-2994.

Jiawei, C., Chen, L., Zhongfang, Y., Jiyuan, W., 2008. Residues and characteristics of organochlorine pesticides in the surface water in the suburb of Beijing. Earth Sci. Front. 15 (5), 242-247. 
Kaushik, A., Sharma, H.R., Jain, S., Dawra, J., Kaushik, C.P., 2008. Pesticide pollution of River Ghaggar in Haryana, India. Environ. Monit. Assess. 160 (1), 61.

Kazakhstan, 2009. National Implementation Plan of the Republic of Kazakhstan on the Obligations under the Stockholm Convention on Persistent Organic Pollutants. In: Agriculture, M.o. (Ed.), National Implementation Plans Stockholm Convention. Astana, p. 36 (KZ). http://chm.pops.int/Implementation/ NationalImplementationPlans/NIPTransmission/tabid/253/Default.aspx

Khuman, S.N., Chakraborty, P., 2019. Air-water exchange of pesticidal persistent organic pollutants in the lower stretch of the transboundary River Ganga, India. Chemosphere 233, 966-974.

Kolok, A.S., Sellin Jeffries, M.K., Knight, L., Snow, D.D., Bartelt-Hunt, S.L., 2014. The hourglass: a conceptual framework for the transport of biologically active compounds from agricultural Landscapes. JAWRA Journal of the American Water Resources Association 50 (2), 266-274.

Kraemer, R., Prishchepov, A.V., Müller, D., Kuemmerle, T., Radeloff, V.C., Dara, A., Terekhov, A., Frühauf, M., 2015. Long-term agricultural land-cover change and potential for cropland expansion in the former Virgin Lands area of Kazakhstan. Environ. Res. Lett. 10 (5), 054012.

Kumar, B., Singh, S.K., Mishra, M., Kumar, S., Sharma, C.S., 2012. Assessment of polychlorinated biphenyls and organochlorine pesticides in water samples from the Yamuna River. Journal of Xenobiotics 2 (1), 6.

Li, Y.F., 1999. Global technical hexachlorocyclohexane usage and its contamination consequences in the environment: from 1948 to 1997. Sci. Total Environ. 232 (3), 121-158.

Long, E., MacDonald, D., 1998. Recommended uses of empirically derived, sediment quality guidelines for marine and estuarine ecosystems. Human and Ecological Risk Assessment 4 (5), 1019-1039.

Long, E.R., Field, L.J., MacDonald, D.D., 1998. Predicting toxicity in marine sediments with numerical sediment quality guidelines. Environ. Toxicol. Chem.: Int. J. 17 (4), 714-727.

Loomis, D., Guyton, K., Grosse, Y., El Ghissasi, F., Bouvard, V., Benbrahim-Tallaa, L., Guha, N., Mattock, H., Straif, K., 2015. Carcinogenicity of lindane, DDT, and 2,4dichlorophenoxyacetic acid. Lancet Oncol. 16 (8), 891-892.

Lozowicka, B, Kaczynski, P., Paritova, A.E., Kuzembekova, G.B, Abzhalieva, A.B., Sarsembayeva, N.B., Alihan, K., 2014. Pesticide residues in grain from Kazakhstan and potential health risks associated with exposure to detected pesticides. Food Chem. Toxicol. 64, 238-248.

MacLeod, S.L., McClure, E.L., Wong, C.S., 2007. Laboratory calibration and field deployment of the Polar Organic Chemical Integrative Sampler for pharmaceuticals and personal care products in wastewater and surface water. Environ. Toxicol. Chem. 26 (12), 2517-2529.

Malik, A., Ojha, P., Singh, K.P., 2009. Levels and distribution of persistent organochlorine pesticide residues in water and sediments of Gomti River (India) - a tributary of the Ganges River. Environ. Monit. Assess. 148 (1-4), 421-435. 
Meyer, T., Lei, Y.D., Wania, F., 2011. Transport of polycyclic aromatic hydrocarbons and pesticides during snowmelt within an urban watershed. Water Res. 45 (3), 1147-1156.

Rasmussen, J.J., Wiberg-Larsen, P., Baattrup-Pedersen, A., Cedergreen, N., McKnight, U.S., Kreuger, J., Jacobsen, D., Kristensen, E.A., Friberg, N., 2015. The legacy of pesticide pollution: an overlooked factor in current risk assessments of freshwater systems. Water Res. 84, 25-32.

Sailaukhanuly, Y., Carlsen, L., Tulegenov, A., Nurzhanova, A., Kenessov, B., Kamysbayev, D., 2016. Distribution and risk assessment of selected organochlorine pesticides in Kyzyl Kairat village from Kazakhstan. Environ. Monit. Assess. 188 (6), 358.

Sellin, M.K., Snow, D.D., Schwarz, M., Carter, B.J., Kolok, A.S., 2009. Agrichemicals in Nebraska, USA, watersheds: occurrence and endocrine effects. Environ. Toxicol. Chem. 28 (11), 2443-2448.

Turgut, C., 2003. The contamination with organochlorine pesticides and heavy metals in surface water in Küçük Menderes River in Turkey, 2000-2002. Environ. Int. 29 (1), 29-32.

Turgut, C., Atatanir, L., Cutright, T.J., 2010. Evaluation of pesticide contamination in Dilek National Park, Turkey. Environ. Monit. Assess. 170 (1-4), 671-679.

Unyimadu, J.P., Osibanjo, O., Babayemi, J.O., 2017. Selected persistent organic pollutants (POPs) in water of River Niger: occurrence and distribution. Environ. Monit. Assess. 190 (1), 6.

USEPA, 1986. Guidelines for Establishing Test Procedures for the Analysis of Pollutants - Definition and Procedure for the Determination of the Method Detection Limit-Revision 1.11. Electronic Code of Federal Regulations Title 40: Protection of Environment(Part 136), Appendix B to Part 136-Definition and Procedure for the Determination of the Method Detection Limit-Revision 131, p. 111.

USEPA, 1998. Guidelines for Ecological Risk Assessment. EPA/630/R-95/002F. US Environmental Protection Agency, Washington, DC USA, p. 188. https://www.epa. gov/risk/guidelines-ecological-risk-assessment

Wang, W., Bai, J., Xi, M., Zhao, Q., Zhang, G., Wen, X., Xiao, R., 2017. Occurrence, sources, and risk assessment of OCPs in surface sediments from urban, rural, and reclamation-affected rivers of the Pearl River Delta, China. Environ. Sci. Pollut. Res. 24 (3), 2535-2548.

Wegerich, K., Van Rooijen, D., Soliev, I., Mukhamedova, N., 2015. Water security in the Syr Darya basin. Water 7 (9), 4657-4684.

World Health Organization, 2020. Pesticide Residues in Food 2019 - Joint FAO/WHO Meeting on Pesticide Residues (JMPR). Italy, Rome, p. 680. https://www.who.int/ foodsafety/areas work/chemical-risks/impr/en/

Yang, D., Qi, S., Zhang, J., Wu, C., Xing, X., 2013. Organochlorine pesticides in soil, water and sediment along the Jinjiang River mainstream to Quanzhou Bay, southeast China. Ecotoxicol. Environ. Saf. 89, 59-65.

Zeng, H., Fu, X., Liang, Y., Qin, L., Mo, L., 2018. Risk assessment of an organochlorine pesticide mixture in the surface waters of Qingshitan Reservoir in Southwest China. RSC Adv. 8 (32), 17797-17805. 


\section{Supplemental Materials}

\section{Legacy and current pesticide residues in Syr Darya, Kazakhstan: Contamination status, seasonal variation and preliminary ecological risk assessment}

Snow, D.D. ${ }^{\mathrm{a}}$, Chakraborty, ${ }^{\mathrm{b}}$., Uralbekov, B ${ }^{\mathrm{c}}$, Satybaldiev B. ${ }^{\mathrm{d}}$, Sallach, J.B. ${ }^{\mathrm{e}}$, Thornton Hampton, L.M. ${ }^{\mathrm{f}}$, Jeffries, M. ${ }^{\mathrm{g}}$, Kolok, A.S. ${ }^{\mathrm{h}}$, and Bartelt-Hunt, S.B. ${ }^{\mathrm{i}}$

\section{Contact information}

${ }^{a}$ Water Sciences Laboratory, 202 Water Sciences Laboratory, University of Nebraska, Lincoln, NE 68583, USA, email: dsnow1@unl.edu

bepartment of Civil Engineering, SRM Institute of Science and Technology, Kancheepuram District, Tamil Nadu 603203, India; email: paromitc@srmist.edu.in

${ }^{c}$ Chemistry and Chemical Technologies, Al-Farabi Kazakh National University, Almaty, Kazakhstan; email: bulat.ural@gmail.com

${ }^{\mathrm{d} C h e m i s t r y}$ and Chemical Technologies, Al-Farabi Kazakh National University, Almaty, Kazakhstan; email: bagdat.satybaldiev@gmail.com

e Department of Environment and Geography, University of York, Heslington, YO10 5NG, UK; email: brett.sallach@york.ac.uk

fDepartment of Biology, Texas Christian University, and University of North Texas, Denton, Texas 76203, USA; email: leahthornton@my.unt.edu

gDepartment of Biology, Texas Christian University, Fort Worth, TX 76129, USA; email: m.jeffries@tcu.edu

hIdaho Water Resources Research Institute, University of Idaho, Moscow, ID, 83844 USA; email: akolok@idaho.edu

iDepartment of Civil Engineering, University of Nebraska, Lincoln, NE 68583, USA; email: sbartelt@unl.edu

Corresponding author: Daniel D. Snow, 202 Water Sciences Laboratory, 1840 N. $37^{\text {th }}$ Street, Lincoln, NE 68583-0844 USA, email: $\underline{\text { dsnow1@unl.edu }}$ 


\section{Contents}

Sampling Locations and Hydrologic Information ................................................................... 3

Table S1 - Geographic coordinates of sampling sites on the Syr Darya river................................ 3

Table S2. Precipitation recorded at Zhetysay, KZ ................................................................... 4

Figure S1. Reported discharge during sampling period, showing inflow conditions near border

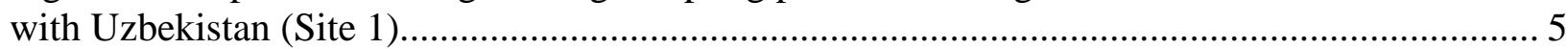

Table S3. Reported discharge (m3/sec) at Keles River in 2015, near Site 1, ............................. 6

Description and Validation of Analytical Methods .................................................................. 7

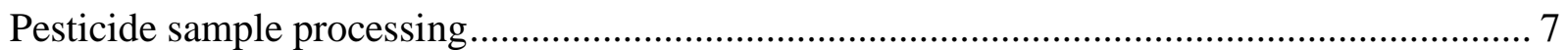

Analysis of Herbicides and Organophosphorus Insecticides .................................................. 7

Table S5. Instrument sensitivity and validation results for herbicide and insecticide method determined from eight replicates of purified reagent water fortified at $0.133 \mu \mathrm{g} / \mathrm{L}$.................... 10

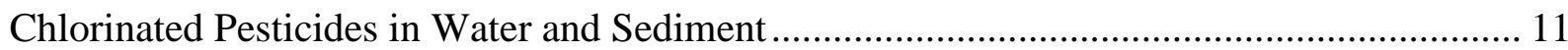

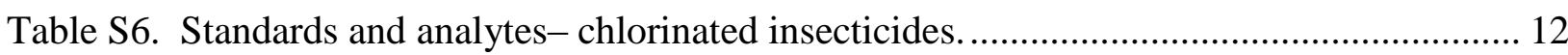

Table S7. Method sensitivity and validation summary - Chlorinated insecticides.................. 13

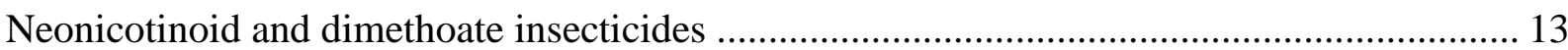

Table S8. Standards and analytes - neonicotinoid and dimethoate insecticide............................. 14

Table S9 Retention times, multiple reaction monitoring (MRM) ions used, and source conditions for neonicotinoid insecticides and dimethoate analysis ............................................................ 15

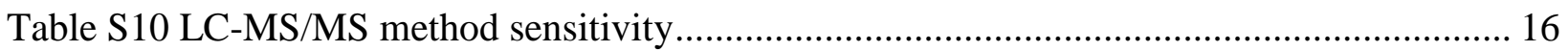

Figure S2: First order kinetics graph over 14-days exposure time ............................................... 17

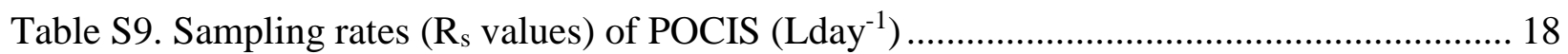

Table S10. Flux estimates of target compounds at (Sites 1 and 2X) in (tonnes x 10-3) day........ 18 
Sampling Locations and Hydrologic Information

Table S1 - Geographic coordinates of sampling sites on the Syr Darya river

\begin{tabular}{|c|c|c|c|}
\hline \multirow[t]{2}{*}{$\begin{array}{l}\text { Sampling } \\
\text { sites }\end{array}$} & \multirow{2}{*}{ Sampling location } & \multicolumn{2}{|c|}{ Geographical coordinates } \\
\hline & & Latitude & Longitude \\
\hline $\mathbf{1}$ & Zhetisay bridge & 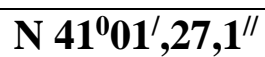 & $\mathrm{E} 068^{0} 13^{\prime} \mathbf{0 7}, 03^{\prime /}$ \\
\hline 2 & Shardara reservoir & $\mathbf{N} 41^{0} 10^{\prime} 24,0^{/ /}$ & E $067^{0} 55^{\prime} 59,1^{\prime \prime}$ \\
\hline $2 X$ & $\begin{array}{l}\text { Syr Darya river after } \\
\text { Shardara reservoir, } \\
\text { stream }\end{array}$ & $\mathbf{N} 41^{0} 15 / 55,1^{\prime /}$ & E $067^{0} 57^{\prime} 14,7^{\prime \prime}$ \\
\hline 3 & Sutkent village & N $41^{0} 55^{\prime} 49,8^{\prime \prime}$ & E $068^{\circ} 42^{\prime} 34,7^{\prime \prime}$ \\
\hline 4 & Arys bridge & $\mathrm{N} 42^{0} 13^{\prime} 16,4^{\prime \prime}$ & E $068^{0} 14^{\prime} 56,9^{\prime /}$ \\
\hline 5 & Koksaray bridge & N 42036 $56,2^{\prime \prime}$ & $\mathrm{E} 068^{0} 13^{\prime} \mathbf{0 7}^{\prime}, \mathbf{0 3}^{/ /}$ \\
\hline
\end{tabular}


Table S2. Precipitation recorded at Zhetysay, KZ $10 \mathrm{~km}$ south of Shadara Reservoir.

Kazhydromet, The Ministry of Environment, Geology and Natural Resources, Republic of

Kazakhstan, Astana, KZ.

\begin{tabular}{|c|c|c|c|c|c|c|c|}
\hline \multicolumn{8}{|c|}{2015} \\
\hline \multicolumn{2}{|c|}{ January } & \multicolumn{2}{|r|}{ February } & \multicolumn{2}{|r|}{ March } & \multicolumn{2}{|r|}{ April } \\
\hline Date & $\begin{array}{c}\text { Precipitation, } \\
\mathrm{mm}\end{array}$ & Date & $\begin{array}{c}\text { Precipitation, } \\
\text { mm }\end{array}$ & Date & $\begin{array}{c}\text { Precipitation, } \\
\mathrm{mm}\end{array}$ & Date & \begin{tabular}{|c|} 
Precipitation, \\
$\mathrm{mm}$
\end{tabular} \\
\hline 2 & 2.5 & 1 & 3.9 & 6 & 0.5 & 1 & 0.6 \\
\hline 3 & 1.8 & 6 & 0 & 7 & 1 & 6 & 0 \\
\hline 5 & 3.5 & 7 & 4 & 9 & 0.4 & 15 & 0.8 \\
\hline 9 & 1.4 & 12 & 14.7 & 10 & 7.6 & 18 & 0.3 \\
\hline 11 & 26.4 & 13 & 0.5 & 20 & 6.8 & 26 & 4 \\
\hline 19 & 1.1 & 14 & 3.8 & 21 & 0.7 & & \\
\hline 20 & 9 & 15 & 11.4 & 22 & 2.7 & & \\
\hline 23 & 2 & 16 & 18.9 & 23 & 1.1 & & \\
\hline 24 & 8.3 & 21 & 4.9 & 24 & 1.6 & & \\
\hline \multirow[t]{4}{*}{31} & 0 & 22 & 7.2 & & & & \\
\hline & & 23 & 5.7 & & & & \\
\hline & & 24 & 3 & & & & \\
\hline & & 25 & 6 & & & & \\
\hline Monthly Totals & 56 & \multicolumn{2}{|r|}{84} & \multirow{2}{*}{\multicolumn{2}{|c|}{22.4}} & \multicolumn{2}{|r|}{5.7} \\
\hline \multicolumn{2}{|c|}{ May } & \multicolumn{2}{|r|}{ June } & & & \multicolumn{2}{|r|}{ August } \\
\hline Date & $\begin{array}{c}\text { Precipitation, } \\
\mathrm{mm}\end{array}$ & Date & $\begin{array}{l}\text { Precipitation, } \\
\mathrm{mm}\end{array}$ & Date & $\begin{array}{c}\text { Precipitation, } \\
\mathrm{mm}\end{array}$ & Date & \begin{tabular}{|c|} 
Precipitation, \\
$\mathrm{mm}$
\end{tabular} \\
\hline 7 & 0.7 & 25 & 0.3 & 18 & 0 & 25 & 0 \\
\hline 8 & 0.3 & & & & & 26 & 1.2 \\
\hline 9 & 6.2 & & & & & 27 & 0 \\
\hline 16 & 9.4 & & & & & & \\
\hline 17 & 0 & & & & & & \\
\hline 24 & 7.1 & & & & & & \\
\hline \multicolumn{2}{|l|}{ Monthly Totals } & \multicolumn{2}{|r|}{0.3} & \multicolumn{2}{|r|}{0} & \multicolumn{2}{|r|}{1.2} \\
\hline \multicolumn{2}{|c|}{ September } & \multicolumn{2}{|r|}{ October } & \multicolumn{2}{|c|}{ November } & \multicolumn{2}{|c|}{ December } \\
\hline Date & \begin{tabular}{|c} 
Precipitation, \\
$\mathrm{mm}$
\end{tabular} & Date & $\begin{array}{c}\text { Precipitation, } \\
\text { mm }\end{array}$ & Date & $\begin{array}{c}\text { Precipitation, } \\
\mathrm{mm}\end{array}$ & Date & \begin{tabular}{|c|} 
Precipitation, \\
$\mathrm{mm}$
\end{tabular} \\
\hline \multirow[t]{10}{*}{19} & 0 & 5 & 0 & 1 & 6.3 & 5 & 0 \\
\hline & & 11 & 4.4 & 2 & 1.4 & 8 & 0 \\
\hline & & 12 & 4.7 & 3 & 1.7 & 9 & 5 \\
\hline & & 14 & 1.8 & 5 & 4 & 10 & 1.2 \\
\hline & & 16 & 0 & 11 & 0 & 20 & 0.3 \\
\hline & & 17 & 2.2 & 12 & 4.1 & 23 & 6 \\
\hline & & 18 & 4.8 & 13 & 4.8 & & \\
\hline & & 22 & 8.5 & 19 & 0.8 & & \\
\hline & & & & 20 & 3.1 & & \\
\hline & & & & 22 & 0 & & \\
\hline Monthly Totals & 0 & & 15.5 & & 12.8 & & 6.3 \\
\hline
\end{tabular}




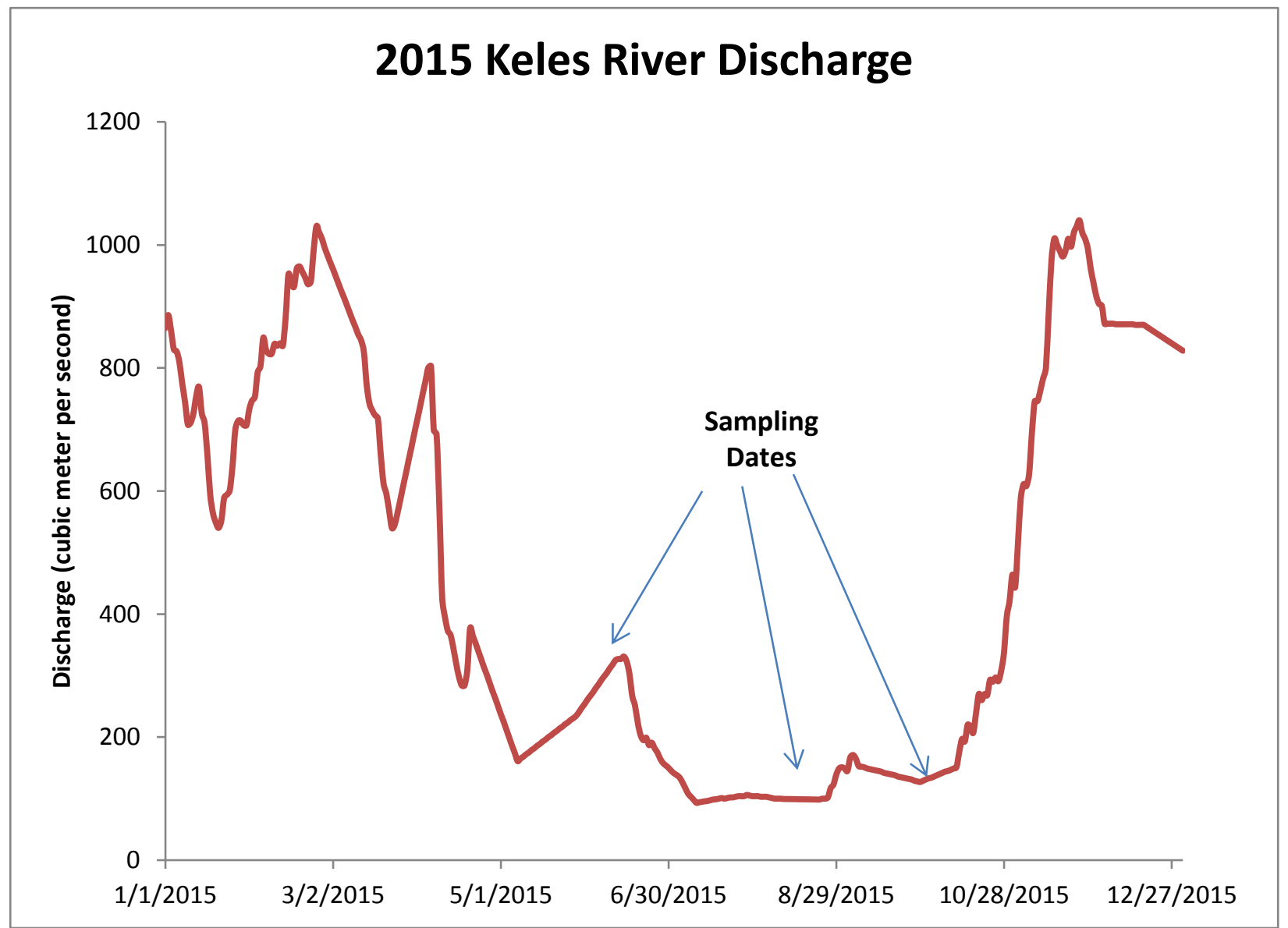

Figure S1. Reported discharge during sampling period, showing inflow conditions near border with Uzbekistan (Site 1). Data obtained from Kazhydromet, The Ministry of Environment, Geology and Natural Resources, Republic of Kazakhstan, Astana, KZ. 
Table S3. Reported discharge (m3/sec) at Keles River in 2015, near Site 1, KazHydroMet,Data obtained from Kazhydromet, The Ministry of Environment, Geology and Natural Resources, Republic of Kazakhstan, Astana, KZ.

\begin{tabular}{|c|c|c|c|c|c|c|c|c|c|c|c|c|}
\hline \multirow{2}{*}{ Date } & \multicolumn{12}{|c|}{ Month } \\
\hline & 1 & 2 & 3 & 4 & 5 & 6 & 7 & 8 & 9 & 10 & 11 & 12 \\
\hline 1 & 865 & 747 & $971^{\wedge}$ & 714 & 237 & 261 & $145^{\wedge}$ & 104 & 149 & 133 & 444 & $904^{\wedge}$ \\
\hline 2 & $886^{\wedge}$ & 753 & 960 & 735 & 225 & 267 & 141 & 103 & 145 & 134 & 515 & $901^{\wedge}$ \\
\hline 3 & 861 & 793 & 948 & 757 & 212 & 273 & 138 & 103 & 167 & 136 & 588 & 872 \\
\hline 4 & 830 & 803 & 936 & 778 & 199 & 280 & 134 & 103 & $171^{\wedge}$ & 138 & 611 & 872 \\
\hline 5 & 827 & 849 & 924 & 800 & 186 & 286 & 126 & 102 & 165 & 140 & 608 & 872 \\
\hline 6 & 809 & 829 & 913 & $803^{\wedge}$ & 174 & 293 & 117 & 101 & 153 & 142 & 628 & 872 \\
\hline 7 & 775 & 823 & 901 & 699 & 161 & 299 & 108 & 100 & 152 & 144 & 695 & 871 \\
\hline 8 & 745 & 823 & 889 & 692 & 165 & 305 & 103 & 100 & 151 & 145 & 746 & 871 \\
\hline 9 & 708 & 839 & 877 & 574 & 168 & 312 & 98.0 & 100 & 149 & 147 & 746 & 871 \\
\hline 10 & 711 & 836 & 866 & 427 & 172 & 318 & 93.1 & 99.5 & 148 & 149 & 763 & 871 \\
\hline 11 & 726 & 840 & 854 & 395 & 175 & 325 & 94.1 & 99.4 & 147 & 151 & 783 & 871 \\
\hline 12 & 754 & 836 & 845 & 373 & 179 & 327 & 94.9 & 99.3 & 146 & 176 & 800 & 871 \\
\hline 13 & 769 & 882 & 826 & 366 & 182 & 327 & 95.7 & 99.3 & 145 & 197 & 890 & 871 \\
\hline 14 & 726 & 952 & 772 & 345 & 186 & $331^{\wedge}$ & 96.3 & 99.2 & 144 & 193 & 975 & 870 \\
\hline 15 & 711 & 938 & 742 & 320 & 189 & 323 & 97.5 & 99.1 & 142 & 220 & 1010 & 870 \\
\hline 16 & 659 & 932 & 731 & 298 & 193 & 303 & 98.6 & 99.0 & 141 & 217 & 1000 & 870 \\
\hline 17 & 595 & 962 & 723 & 284 & 196 & 267 & 99.0 & 98.9 & 140 & 207 & 990 & 870 \\
\hline 18 & 564 & 965 & 718 & 284 & 200 & 251 & 100 & 98.9 & 139 & 239 & 981 & 867 \\
\hline 19 & 549 & 956 & 661 & 309 & 203 & 223 & 101 & 98.8 & 138 & 270 & 990 & 864 \\
\hline 20 & 540 & 947 & 613 & 377 & 207 & 203 & 100 & 98.7 & 136 & 260 & 1010 & 861 \\
\hline 21 & 552 & 936 & 596 & 364 & 210 & 195 & 101 & 98.6 & 135 & 270 & 997 & 858 \\
\hline 22 & 589 & 940 & 569 & 352 & 214 & 199 & 102 & 98.6 & 134 & 268 & 1020 & 855 \\
\hline 23 & 594 & 990 & 540 & 339 & 217 & 187 & 102 & 98.5 & 133 & 293 & 1030 & 852 \\
\hline 24 & 601 & $1030^{\wedge}$ & 545 & 326 & 221 & 191 & 103 & 100 & 132 & 290 & $1040^{\wedge}$ & 849 \\
\hline 25 & 641 & 1020 & 564 & 313 & 224 & 182 & 104 & 100 & 131 & 297 & 1020 & 846 \\
\hline 26 & 700 & 1010 & 585 & 301 & 228 & 175 & 104 & 102 & 129 & 291 & 1010 & 843 \\
\hline 27 & 714 & 995 & 607 & 288 & 231 & 165 & 104 & 117 & 128 & 308 & 994 & 840 \\
\hline 28 & 714 & 983 & 628 & 275 & 235 & 158 & 106 & 123 & 127 & 337 & 962 & 837 \\
\hline 29 & 707 & & 650 & 263 & 241 & 154 & 105 & 139 & 129 & 396 & 939 & 834 \\
\hline 30 & 707 & & 671 & 250 & 248 & $150_{-}$ & 104 & $149^{\wedge}$ & 131 & 421 & 917 & 831 \\
\hline 31 & 733 & & 693 & & $254^{\wedge}$ & & 104 & 151 & & $464^{\wedge}$ & & 828 \\
\hline
\end{tabular}


Description and Validation of Analytical Methods

Pesticide sample processing

Water samples for pesticide analysis were collected in 1-liter square amber glass bottles were divided into three $300 \mathrm{~mL}$ portions for solid phase extraction (SPE) within a few days of collection and subsequent analysis by 3 instrumental methods. This approach takes advantage of preservation effect and ease of transporting SPE cartridges in place of water samples collected from remote areas for instrumental analysis at a later date. Two portions were spiked and equilibrated with 2,000 ng terbuthylazine and butachlor surrogates and immediately extracted using preconditioned $1 \mathrm{~g}$ trifunctional tC18 bonded silica SPE cartridges. The third $300 \mathrm{~mL}$ portion was extracted onto a $200 \mathrm{mg}$ HLB SPE cartridge (Waters Corporation, Milford MA). Reverse phase tC18 cartridges were preconditioned onsite by passing $5 \mathrm{~mL}$ of ethyl acetate, 5 $\mathrm{mL}$ of acetonitrile and $5 \mathrm{~mL}$ of purified (deionized distilled) reagent water, while the more polar HLB cartridges were preconditioned using $5 \mathrm{~mL}$ acetonitrile followed by $5 \mathrm{~mL}$ of purified reagent water immediately prior to use.

Following extraction, each SPE cartridge was dried via vacuum aspiration at room temperature for $5 \mathrm{~min}$, and then stored in sealed zipper bags at 4oC. Processed SPE cartridges containing extracted residues were transported to the University of Nebraska Water Sciences Laboratory (UN-WSL) and stored at $-20^{\circ} \mathrm{C}$ until further processing. One of the two tC18 cartridges from each sample was utilized for the analysis of 22 non-organochlorine pesticides, while the other was utilized for the analysis of eight organochlorine pesticides. The HLB cartridges were processed for the analysis of 5 neonicotinoid and one organophosphate insecticide.

\section{Analysis of Herbicides and Organophosphorus Insecticides}

Method is based on Cassada et al 1994 (modified to accommodate additional analytes)

and is suitable for analysis of a wide variety of organic compounds that are efficiently partitioned from an aqueous matrix onto a C18 organic phase chemically bonded to a solid silica packing material. The compounds must be sufficiently volatile and thermally stable for analysis by gas chromatography. As used at the Water Sciences Laboratory, the method is ideally suited for low ppb and sub-ppb analysis of pesticide and metabolite residues in water. The method is especially suited for analysis of dissolved atrazine, and two of its metabolites, deethylatrazine and deisopropylatrazine, since quantitation for these compounds is based on isotope dilution utilizing 
${ }^{13} \mathrm{C}_{3}$-labelled internal standards which corrects for any recovery losses during the extraction. Quantitation of other pesticides is based on the ${ }^{13} \mathrm{C}_{3}$-atrazine internal standard. Method detection limits vary with compound and range from $\sim 0.01 \mu \mathrm{g} / \mathrm{L}$ for atrazine to $0.10 \mu \mathrm{g} / \mathrm{L}$ for cyanazine. The calibration range of target compounds in this method is from 0.25 to $32.5 \mathrm{ng} / \mu \mathrm{L}$ and internal standards are at $25 \mathrm{ng} / \mu \mathrm{L}$.

Target compounds, internal standards (IS) and surrogate properties are listed in table S1. Stock solutions are prepared from neat reference standards obtained from Sigma-Aldrich (St. Louis, MO USA) and Crescent Chemical. After weighing each sample or blank, surrogates are spiked at $2000 \mathrm{ng}$ and equilibrated prior to extraction onto preconditioned 1-gram tC18 cartridges (\#WAT036800) under vacuum at a flow rate between 5-10 mL/min. Cartridges are dried by passing air under vacuum for 10 minutes after entire sample has been extracted. Cartridges are eluted with $6 \mathrm{~mL}$ of ethyl acetate, solvent spiked with internal standards and slowly evaporated under dry nitrogen. Residual water is removed with anhydrous sodium sulfate during the concentration process and quantitatively transferred to clean borosilicate culture tubes using additional ethyl acetate. Each extract is evaporated completely, residues dissolved in 200 $\mu \mathrm{L}$ ethyl acetate, and finally transferred to a $300 \mu \mathrm{L}$ silane-treated glass insert.

Table S4. Standards and analytes - herbicides and organophosphorus insecticides

\begin{tabular}{|c|c|c|c|c|c|}
\hline Analyte & $\begin{array}{l}\text { CAS } \\
\text { Number }\end{array}$ & Mol. Formula & $\begin{array}{l}\text { Mol. Weight } \\
(\mathrm{g} / \mathrm{mol})\end{array}$ & $\begin{array}{l}\text { Quantitative } \\
\text { Ion }(\mathbf{m} / \mathbf{z})\end{array}$ & Structure \\
\hline${ }^{13} \mathrm{C}_{3}$-Atrazine (IS) & $1443685-80-0$ & ${ }^{13} \mathrm{C}_{3} \mathrm{C}_{5} \mathrm{H}_{14} \mathrm{ClN}_{5}$ & 218.70 & 203 & \\
\hline${ }^{13} \mathrm{C}-\mathrm{DEA}$ (IS) & $\mathrm{XxXX}-\mathrm{XX}-\mathrm{X}$ & ${ }^{13} \mathrm{C}_{3} \mathrm{C}_{3} \mathrm{H}_{10} \mathrm{ClN}_{5}$ & 190.83 & 175 & \\
\hline${ }^{13} \mathrm{C}$-DIA (IS) & $\mathrm{XXXX}-\mathrm{XX}-\mathrm{X}$ & ${ }^{13} \mathrm{C}_{3} \mathrm{C}_{2} \mathrm{H}_{8} \mathrm{ClN}_{5}$ & 176.80 & 176 & \\
\hline Butachlor (Surrogate) & 23184-66-9 & $\mathrm{C}_{17} \mathrm{H}_{26} \mathrm{ClNO}_{2}$ & 311.85 & 176 & \\
\hline $\begin{array}{l}\text { Terbuthylazine } \\
\text { (Surrogate) }\end{array}$ & $5915-41-3$ & $\mathrm{C}_{9} \mathrm{H}_{16} \mathrm{ClN}_{5}$ & 229.71 & 214 & \\
\hline Acetochlor & $34256-82-1$ & $\mathrm{C}_{14} \mathrm{H}_{20} \mathrm{ClNO}_{2}$ & 269.767 & 146 & \\
\hline
\end{tabular}




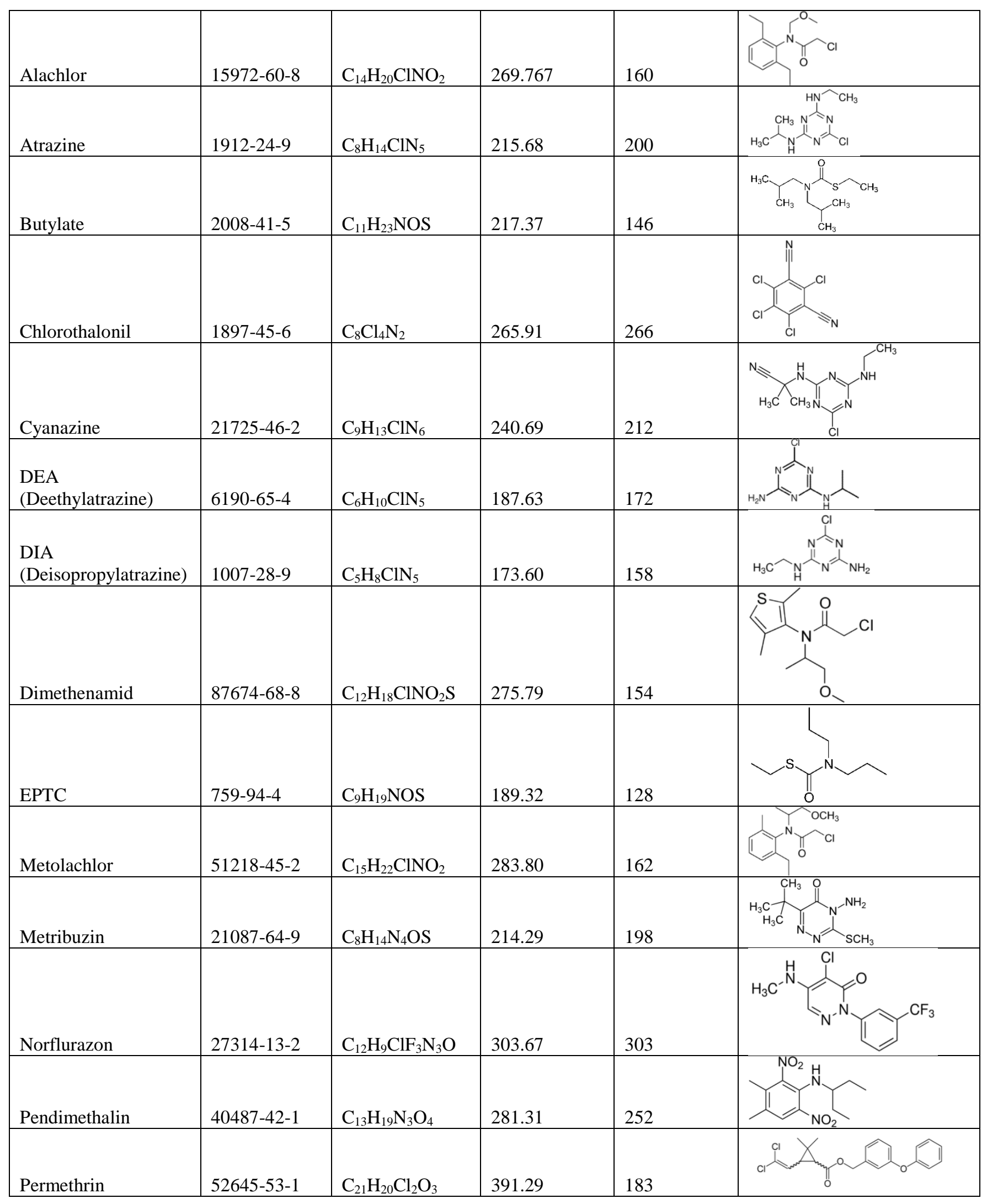




\begin{tabular}{|c|c|c|c|c|c|}
\hline Prometon & $1610-18-0$ & $\mathrm{C}_{10} \mathrm{H}_{19} \mathrm{~N}_{5} \mathrm{O}$ & 225.29 & 210 & H \\
\hline Propachlor & $1918-16-7$ & $\mathrm{C}_{11} \mathrm{H}_{14} \mathrm{ClNO}$ & 211.69 & 120 & $\mathrm{H}_{3}$ \\
\hline Propazine & $139-40-2$ & $\mathrm{C}_{9} \mathrm{H}_{16} \mathrm{ClN}_{5}$ & 229.71 & 214 & \\
\hline Simazine & $122-34-9$ & $\mathrm{C}_{7} \mathrm{H}_{12} \mathrm{ClN}_{5}$ & 201.66 & 201 & \\
\hline Tefluthrin & $79538-32-2$ & $\mathrm{C}_{17} \mathrm{H}_{14} \mathrm{ClF}_{7} \mathrm{O}_{2}$ & 418.74 & 177 & \\
\hline Terbufos & $13071-79-9$ & $\mathrm{C}_{9} \mathrm{H}_{21} \mathrm{O}_{2} \mathrm{PS}_{3}$ & 288.42 & 231 & \\
\hline Trifluralin & 1582-09-8 & $\mathrm{C}_{13} \mathrm{H}_{16} \mathrm{~F}_{3} \mathrm{~N}_{3} \mathrm{O}_{4}$ & 335.28 & 306 & \\
\hline
\end{tabular}

Table S5. Instrument sensitivity and validation results for herbicide and insecticide method determined from eight replicates of purified reagent water fortified at $0.133 \mu \mathrm{g} / \mathrm{L}$.

\begin{tabular}{|l|r|r|r|r|}
\hline \multicolumn{1}{|c|}{$\begin{array}{c}\text { Instrument } \\
\text { Detection Limit } \\
(\mathbf{p g})\end{array}$} & $\begin{array}{c}\text { Method } \\
\text { Detection Limit } \\
(\boldsymbol{\mu g} / \mathbf{L})\end{array}$ & $\begin{array}{c}\text { Recovery } \\
\mathbf{( \% )}\end{array}$ & \multicolumn{2}{c|}{$\begin{array}{c}\text { Standard } \\
\text { Deviation } \\
(\%)\end{array}$} \\
\hline Acetochlor & 16.5 & 0.008 & 123.30 & 1.83 \\
\hline Alachlor & 25.5 & 0.011 & 126.24 & 1.34 \\
\hline Atrazine & 5.9 & 0.005 & 107.48 & 2.41 \\
\hline Butylate & 12.8 & 0.092 & 109.01 & 3.05 \\
\hline Chlorthalonil & 29.3 & 0.018 & 141.67 & 0.75 \\
\hline Cyanazine & 26.7 & 0.227 & 51.27 & 48.23 \\
\hline DEA & 2.9 & 0.038 & 179.79 & 2.74 \\
\hline DIA & 15.9 & 0.132 & 78.14 & 38.95 \\
\hline Dimethenamid & 22.0 & 0.013 & 125.19 & 7.31 \\
\hline EPTC & 9.2 & 0.099 & 101.03 & 17.70 \\
\hline Metolachlor & 9.6 & 0.009 & 109.29 & 3.41 \\
\hline Metribuzin & 28.5 & 0.018 & 46.52 & 57.20 \\
\hline Norflurazon & 80.6 & 0.013 & 108.95 & 2.47 \\
\hline Pendimethalin & 8.4 & 0.014 & 68.14 & 7.69 \\
\hline Permethrin & 91.1 & 0.042 & 22.42 & 16.23 \\
\hline Prometon & 7.7 & 0.036 & 39.83 & 9.52 \\
\hline Propachlor & 3.9 & 0.023 & 34.69 & 16.29 \\
\hline Propazine & 5.4 & 0.007 & 120.20 & 8.19 \\
\hline Simazine & 25.5 & 0.007 & 95.52 & 6.33 \\
\hline Tefluthrin & 4.0 & 0.034 & 98.95 & 1.90 \\
\hline Terbufos & 112.2 & 0.183 & 46.6 & 26.2 \\
\hline Trifluralin & 5.8 & 0.016 & 44.58 & 9.21 \\
\hline
\end{tabular}




\section{Chlorinated Pesticides in Water and Sediment}

Target compounds, internal standards, and surrogate properties are listed in table S1.

Stock solutions are prepared from neat reference materials dissolved in methanol or by dilution of commercially available standard mixes. After weighing each sample or blank, surrogates are spiked (2000 ng) and equilibrated prior to extraction onto preconditioned 1-gram tC18 cartridges (\#WAT036800) under vacuum at a flow rate between 5-10 $\mathrm{mL} / \mathrm{min}$. Cartridges are dried by passing air under vacuum for 10 minutes after entire sample has been extracted. Elution uses 3 $\mathrm{mL}$ of acetone, followed by $3 \mathrm{~mL}$ of hexane, and $3 \mathrm{~mL}$ of ethyl acetate. Solvent eluate was spiked with internal standards, and slowly evaporated under dry nitrogen. Residual water was removed with anhydrous sodium sulfate during the concentration process and quantitatively transferred to clean borosilicate culture tubes using additional ethyl acetate. Each extract was evaporated completely, residues dissolved in $200 \mu \mathrm{L}$ ethyl acetate, and finally transferred to a $300 \mu \mathrm{L}$ silane-treated glass insert for analysis of chlorinated insecticides listed in Table S3.

Sediment samples were processed using microwave-assisted solvent extraction. Briefly, five (5.00) grams of wet sample is weighed into a 10 milliter $(\mathrm{mL})$ Teflon $^{\mathrm{TM}}$ microwave digestion vessel, and thoroughly mixed with $6 \mathrm{~mL}$ of acetonitrile and $200 \mathrm{ng}$ of surrogate compounds. Batches of up to 40 samples are then subjected to microwave irradiation (400W) for 10 minutes at $90^{\circ} \mathrm{C}$ using a CEM MARS Xpress (Matthews, NC USA) microwave digestion system. After cooling and decanting solvent, sediment is mixed with an additional $6 \mathrm{~mL}$ of acetonitrile, allowed to settle and then solvent combined with the first portion. Extract volume is then reduced to near 1-2 $\mathrm{mL}$ under dry nitrogen. The acetonitrile is mixed with $100 \mathrm{~mL}$ of water, and extracts purified by reverse phase (C18) solid phase extraction (SPE) cartridges following the same procedure as for water samples described above. Absorbed compounds are then eluted with ethyl acetate, spiked with $50 \mathrm{ng}$ of isotope-labelled internal standards $(10 \mathrm{ng} / \mathrm{g})$ and analyzed by GC/MS as described above.

Calibration standards are prepared over the range of 0.25 to $32.5 \mathrm{ng} / \mu \mathrm{L}$ in Optima (Fisher Scientific) ethyl acetate from commercially-available mixes (EPA 8081 Pesticide Standard Mix, Sigma-Aldrich, St. Louis, MO) and includes isotopically-labelled internal standard at $25 \mathrm{ng} / \mu \mathrm{L}$ of ${ }^{13} \mathrm{C}_{3}$-atrazine (Merck Sharp \& Dohme/Isotopes). Separation for both sets of extracts uses a HP-1MS chromatography column, $30 \mathrm{M}$ x $0.25 \mathrm{~mm}$ ID, $0.25 \mu \mathrm{m}$ film (Max Temp: $360^{\circ} \mathrm{C}$ ), with helium (He) carrier gas. Pulsed split-less injection is used with initial pressure: 3.97 psi and 
pulsed pressure: 25.0 psi. Pulse time: $0.75 \mathrm{~min}$. Pulsed flow: $50.0 \mathrm{~mL} / \mathrm{min}$. Purge time: $0.75 \mathrm{~min}$. Total flow: $53.4 \mathrm{~mL} / \mathrm{min}$. Gas saver: On. Saver flow: $20 \mathrm{~mL} / \mathrm{min}$. Saver time: $1.50 \mathrm{~min}$. Injection temp: $260^{\circ} \mathrm{C}$. MS transfer line temp: $280^{\circ} \mathrm{C}$. Gradient temp: $80^{\circ} \mathrm{C}$ for $0.75 \mathrm{~min}, 40.0^{\circ} \mathrm{C} / \mathrm{min}$ to $170^{\circ} \mathrm{C}, 2.5^{\circ} \mathrm{C} / \mathrm{min}$ to $236^{\circ} \mathrm{C}$, then $40.0^{\circ} \mathrm{C} / \mathrm{min}$ to $275^{\circ} \mathrm{C}$, hold $9.62 \mathrm{~min}$. Run time: $40.0 \mathrm{~min}$. 1 $\mu \mathrm{L}$ injection. Instrument Detection Limits were estimated from 8 replicates of the lowest calibration standard $(0.25 \mathrm{ng} / \mu \mathrm{L})$.

Aqueous method validation samples for the chlorinated pesticides (tC18 cartridge 2) are prepared at 300 milliliters purified reagent water spiked at $0.3 \mu \mathrm{g} / \mathrm{L}$ and analyzed according to the procedure describe above on 5973 GC-MSD. Sediment method validation used 8 portions of clean sand spiked at $4 \mathrm{ng} / \mathrm{g}$ and processed as samples. Results of instrument and both sets of validation experiments are summarized in Table S7.

Table S6. Standards and analytes-chlorinated insecticides.

\begin{tabular}{|c|c|c|c|c|c|}
\hline Analyte & CAS Number & Mol. Formula & $\begin{array}{l}\text { Mol. Weight } \\
\text { (g/mol) }\end{array}$ & $\begin{array}{l}\text { Quantitative } \\
\text { Ion }(\mathbf{m} / \mathbf{z})\end{array}$ & Structure \\
\hline $\begin{array}{l}{ }^{13} \mathrm{C}_{3} \text {-Atrazine } \\
\text { (IS) }\end{array}$ & $1443685-80-0$ & ${ }^{13} \mathrm{C}_{3} \mathrm{C}_{5} \mathrm{H}_{14} \mathrm{ClN}_{5}$ & 218.70 & 203 & \\
\hline $\begin{array}{l}\text { Terbuthylazine } \\
\text { (Surrogate) }\end{array}$ & $5915-41-3$ & $\mathrm{C}_{9} \mathrm{H}_{16} \mathrm{ClN}_{5}$ & 229.71 & 214 & \\
\hline Trifluralin & $1582-09-8$ & $\mathrm{C}_{13} \mathrm{H}_{16} \mathrm{~F}_{3} \mathrm{~N}_{3} \mathrm{O}_{4}$ & 335.28 & 306 & \\
\hline $\begin{array}{l}\gamma-\mathrm{HCH} \\
\text { (Lindane) }\end{array}$ & $58-89-9$ & $\mathrm{C}_{6} \mathrm{H}_{6} \mathrm{Cl}_{6}$ & 290.83 & 181 & \\
\hline Heptachlor & $76-44-8$ & $\mathrm{C}_{10} \mathrm{H}_{5} \mathrm{Cl}_{7}$ & 373.32 & 272 & \\
\hline Aldrin & $309-00-2$ & $\mathrm{C}_{12} \mathrm{H}_{8} \mathrm{Cl}_{6}$ & 364.90 & 263 & \\
\hline 4,4-DDE & $72-55-9$ & $\mathrm{C}_{14} \mathrm{H}_{8} \mathrm{Cl}_{4}$ & 318.03 & 318 & \\
\hline
\end{tabular}




\begin{tabular}{|c|c|c|c|c|c|}
\hline Dieldrin & $60-57-1$ & $\mathrm{C}_{12} \mathrm{H}_{8} \mathrm{Cl}_{6} \mathrm{O}$ & 380.91 & 79 & \\
\hline Endrin & $72-20-8$ & $\mathrm{C}_{12} \mathrm{H}_{8} \mathrm{Cl}_{6} \mathrm{O}$ & 380.91 & 263 & \\
\hline 4,4-DDT & $50-29-3$ & $\mathrm{C}_{14} \mathrm{H}_{9} \mathrm{Cl}_{5}$ & 354.49 & 235 & \\
\hline
\end{tabular}

Table S7. Method sensitivity and validation summary - Chlorinated insecticides.

\begin{tabular}{|c|c|c|c|c|c|c|c|}
\hline \multirow[b]{2}{*}{ Compound } & \multirow[b]{2}{*}{$\begin{array}{l}\text { Instrument } \\
\text { Detection } \\
\text { Limit (pg) }\end{array}$} & \multicolumn{3}{|c|}{$\begin{array}{l}\text { Water extraction method determined } \\
\text { in reagent water fortified at } 0.3 \mu \mathrm{g} / \mathrm{L} \text {. }\end{array}$} & \multicolumn{3}{|c|}{$\begin{array}{l}\text { Sediment extraction method } \\
\text { determined in clean sand fortified } \\
\text { at } 4 \mathrm{ng} / \mathrm{g} \text {. }\end{array}$} \\
\hline & & $\begin{array}{c}\text { Method } \\
\text { Detection } \\
\text { Limit }(\mu \mathrm{g} / \mathrm{L}) \\
\end{array}$ & $\begin{array}{c}\text { MDL } \\
\text { Recovery } \\
(\%)\end{array}$ & $\begin{array}{c}\text { Standard } \\
\text { Deviation } \\
(\%) \\
\end{array}$ & $\begin{array}{c}\text { Method } \\
\text { Detection } \\
\text { Limit } \\
(\mathrm{ng} / \mathrm{g}) \\
\end{array}$ & $\begin{array}{c}\text { MDL } \\
\text { Recovery } \\
(\%)\end{array}$ & $\begin{array}{c}\text { Standard } \\
\text { Deviation } \\
(\%) \\
\end{array}$ \\
\hline 4,4-DDE & 15.4 & 0.007 & 38.2 & 2.5 & 2.1 & 112.9 & 26.0 \\
\hline 4,4-DDT & 12.4 & 0.019 & 24.7 & 10.5 & 2.9 & 87.0 & 44.2 \\
\hline a-HCH & 11.7 & 0.036 & 85.8 & 5.7 & 2.0 & 93.7 & 30.8 \\
\hline Aldrin & 16.5 & 0.053 & 19.5 & 43.7 & 2.2 & 125.6 & 24.5 \\
\hline$\beta-\mathrm{HCH}$ & 40.6 & 0.034 & 94.1 & 4.9 & 1.6 & 94.6 & 32.1 \\
\hline$\delta$-HCH & 20.8 & 0.051 & 99.4 & 6.7 & 1.9 & 133.4 & 20.5 \\
\hline Dieldrin & 23.1 & 0.027 & 91.1 & 3.7 & 5.0 & 136.7 & 41.6 \\
\hline$\gamma$-HCH (Lindane) & 10.0 & 0.026 & 106.5 & 3.1 & 2.7 & 117.1 & 29.6 \\
\hline Heptachlor & 4.6 & 0.026 & 28.9 & 11.7 & 1.5 & 52.8 & 35.0 \\
\hline
\end{tabular}

Neonicotinoid and dimethoate insecticides

Sample extracts are concentrated using 200 milligram polymeric (Waters HLB) SPE cartridges or polar organic contaminant integrative samplers (POCIS) containing the same sorbent material. Standards for each of the target analytes, as well as isotopically-labelled standards (d4-Imidacloprid, d3-Thiamethoxam and d6-Metalaxyl), were obtained from Sigma Aldrich (St. Louis, MO). Each HLB SPE cartridge was eluted under vacuum with $6 \mathrm{~mL}$ of high purity methanol (Optima, Fisher Scientific, St. Louis, MO), the eluate was spiked with 50 $\mu \mathrm{L}$ of $1.0 \mathrm{ng} / \mu \mathrm{L}$ internal standard mix, and completely evaporated under dry nitrogen in borosilicate culture tubes. Residue is re-dissolved in $50 \mu \mathrm{L}$ high purity methanol and mixed with $200 \mu \mathrm{L}$ purified (distilled deionized, organic free) reagent water prior to analysis by LC-MS/MS. 
A pseudo-molecular ion $[\mathrm{M}+\mathrm{H}]^{+}$is selected as the parent ion for fragmentation, and corresponding fragment ion(s) is selected for identification and quantitation. Ionization and collision energies are optimized based on procedures described by the instrument manufacturer. A Quattro-Micro triple quadrupole mass spectrometer equipped with an APCI source in positive ion mode was used for multiple reaction monitoring (MRM). The argon collision gas was 4.0x10-3 torr, desolvation gas: was nitrogen at $600 \mathrm{~L} / \mathrm{hr}$. Desolvation temperature was $425^{\circ} \mathrm{C}$, cone gas was nitrogen at $50 \mathrm{~L} / \mathrm{hr}$. Source temperature was $150^{\circ} \mathrm{C}$, capillary was held at $4 \mathrm{kV}$, extractor: $6 \mathrm{~V}$, multiplier at $750 \mathrm{eV}$, entrance $-5 \mathrm{~V}$ andexit $1 \mathrm{~V}$. Cone voltages and collision energies used for each standard and analyte are given in Table S7.

Table S8. Standards and analytes - neonicotinoid and dimethoate insecticides. Internal standards (IS), surrogates and analytes measured using liquid chromatography-tandem mass spectrometry (LC-MS/MS)

\begin{tabular}{|c|c|c|c|c|}
\hline Compound & $\begin{array}{l}\text { CAS } \\
\text { number }\end{array}$ & Formula & $\begin{array}{l}\text { Mol Wt. } \\
\text { (g/mol) }\end{array}$ & Structure \\
\hline Clothianidin $-\mathrm{d} 3$ (IS) & & ${ }^{2} \mathrm{H}_{3} \mathrm{C}_{6} \mathrm{H}_{5} \mathrm{ClN}_{5} \mathrm{O}_{2} \mathrm{~S}$ & 252.67 & \\
\hline Imidacloprid - d4 (IS) & & ${ }^{2} \mathrm{H}_{4} \mathrm{C}_{9} \mathrm{H}_{6} \mathrm{ClN}_{5} \mathrm{O}_{2}$ & 259.66 & \\
\hline $\begin{array}{l}\text { Metalaxyl - d6 } \\
\text { (IS) }\end{array}$ & & ${ }^{2} \mathrm{H}_{6} \mathrm{C}_{15} \mathrm{H}_{15} \mathrm{NO}_{4}$ & 285.33 & \\
\hline $\begin{array}{l}\text { Pyraclostrobin - d3 } \\
\text { (IS) }\end{array}$ & & ${ }^{2} \mathrm{H}_{3} \mathrm{C}_{19} \mathrm{H}_{15} \mathrm{ClN}_{3} \mathrm{O}_{4}$ & 390.82 & \\
\hline $\begin{array}{l}\text { Thiamethoxam - d3 } \\
\text { (IS) }\end{array}$ & & ${ }^{2} \mathrm{H}_{3} \mathrm{C}_{8} \mathrm{H}_{7} \mathrm{ClN}_{5} \mathrm{O}_{3} \mathrm{~S}$ & 294.71 & \\
\hline $\begin{array}{l}\text { Nitenpyram } \\
\text { (Surrogate) }\end{array}$ & $150824-47-8$ & $\mathrm{C}_{11} \mathrm{H}_{15} \mathrm{ClN}_{4} \mathrm{O}_{2}$ & 270.72 & \\
\hline $\begin{array}{l}\text { Terbutylazine } \\
\text { (Surrogate) }\end{array}$ & $5915-41-3$ & $\mathrm{C}_{9} \mathrm{H}_{16} \mathrm{ClN}_{5}$ & 229.71 & \\
\hline Acetamiprid & $135410-20-7$ & $\mathrm{C}_{10} \mathrm{H}_{11} \mathrm{ClN}_{4}$ & 460.434 & \\
\hline Clothianidin & $210880-92-5$ & $\mathrm{C}_{6} \mathrm{H}_{8} \mathrm{ClN}_{5} \mathrm{O}_{2} \mathrm{~S}$ & 249.67 & \\
\hline Dinotefuran & $165252-70-0$ & $\mathrm{C}_{7} \mathrm{H}_{14} \mathrm{~N}_{4} \mathrm{O}_{3}$ & 202.21 & \\
\hline
\end{tabular}




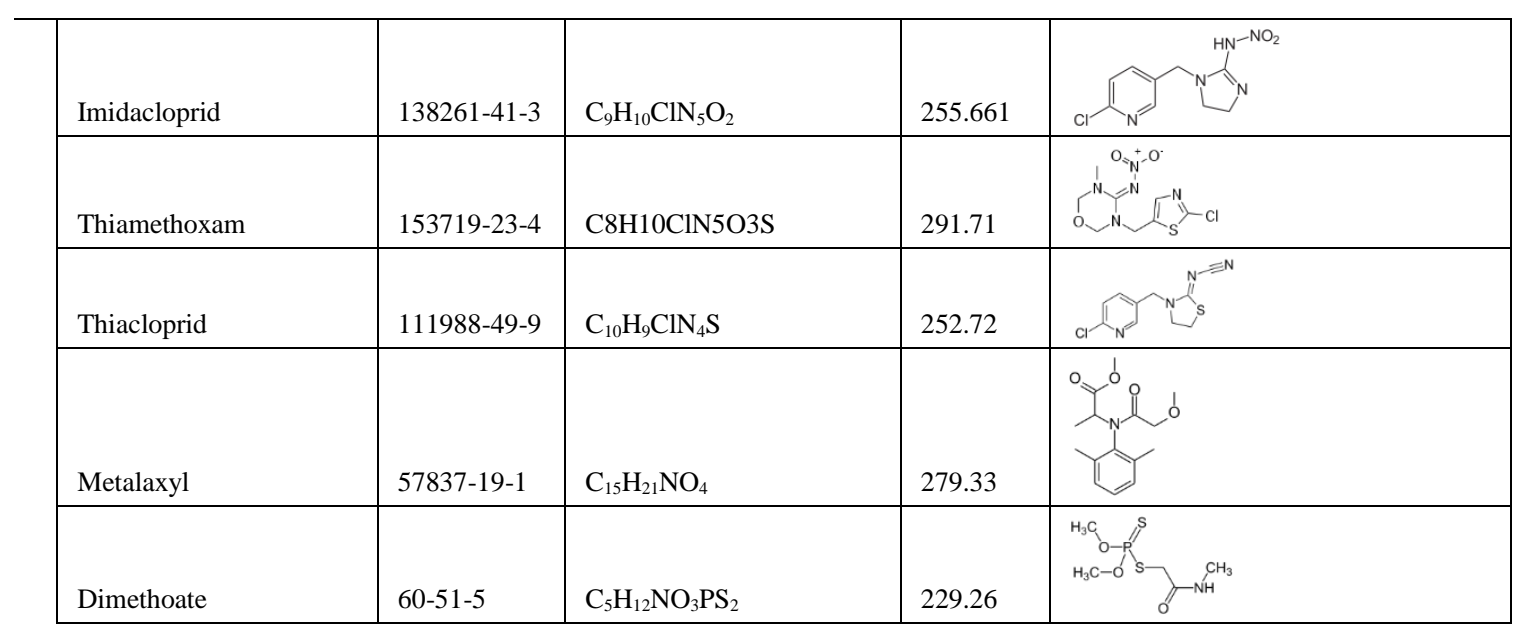

Table S9 Retention times, multiple reaction monitoring (MRM) ions used, and source conditions for neonicotinoid insecticides and dimethoate analysis. ("*” indicates internal standard and "**" indicates surrogate compound.

\begin{tabular}{|l|c|c|c|c|c|}
\hline Compound & $\begin{array}{c}\text { Parent Ion } \\
(\mathbf{m} / \mathbf{z})\end{array}$ & $\begin{array}{c}\text { Product } \\
\text { Ion }(\mathbf{m} / \mathbf{z})\end{array}$ & $\begin{array}{c}\text { Cone } \\
\text { Voltage (V) }\end{array}$ & $\begin{array}{c}\text { Collision } \\
\text { Energy (eV) }\end{array}$ & $\begin{array}{c}\text { Retention time } \\
(\mathbf{m i n})\end{array}$ \\
\hline Acetamiprid & 223.1 & 126.1 & 27 & 18 & 6.88 \\
\hline Clothianidin & 250.1 & 169 & 19 & 18 & 6.63 \\
\hline Clothianidin-d3* & 253.1 & 172 & 19 & 18 & 6.63 \\
\hline Dimethoate & 229.8 & 124.7 & 18 & 17 & 6.88 \\
\hline Dinotefurn & 203.1 & 129 & 12 & 12 & 5.89 \\
\hline Imidacloprid & 256 & 209.3 & 27 & 18 & 6.55 \\
\hline Imidacloprid-d4* & 260 & 213.1 & 27 & 18 & 6.55 \\
\hline Metalaxyl & 280.1 & 220.2 & 20 & 13 & 9.03 \\
\hline Metalaxyl-d6* & 286.1 & 226.2 & 20 & 13 & 9.03 \\
\hline Thiacloprid & 253 & 126 & 28 & 22 & 7.04 \\
\hline Thiamethoxam & 292.1 & 211 & 27 & 18 & 6.30 \\
\hline Thiamethoxam-d3* & 295.1 & 214 & 27 & 18 & 6.30 \\
\hline Terbuthylazine** & 230 & 174 & 33 & 17 & 10.35 \\
\hline Nitenpyram** & 271 & 126 & 15 & 27 & 5.97 \\
\hline
\end{tabular}


Table S10 LC-MS/MS method sensitivity determined from variability of low calibration standard (12.5 pg/uL) analyzed using atmospheric pressure chemical ionization LC-MS/MS. Method detection limit determined from eight replicate extractions of $100 \mathrm{~mL}$ portions of purified reagent water fortified at $0.020 \mathrm{ug} / \mathrm{L}$ of target compounds.

\begin{tabular}{|l|r|r|r|r|}
\hline Compound & $\begin{array}{c}\text { Instrument } \\
\text { Detection } \\
\text { Limit }(\mathrm{pg})\end{array}$ & $\begin{array}{c}\text { Method } \\
\text { Detection } \\
\text { Limit } \\
(\mathrm{ug} / \mathrm{L})\end{array}$ & $\begin{array}{c}\text { Recovery } \\
(\%)\end{array}$ & $\begin{array}{c}\text { Standard } \\
\text { Deviation } \\
(\%)\end{array}$ \\
\hline Acetamiprid & 99.4 & 0.007 & 109.8 & 11.8 \\
\hline Clothianidin & 314.3 & 0.009 & 106.2 & 15.0 \\
\hline Dinotefuran & 221.7 & 0.011 & 93.2 & 21.4 \\
\hline Imidacloprid & 226.8 & 0.010 & 115.7 & 15.6 \\
\hline Thiamethoxam & 202.0 & 0.021 & 102.7 & 35.4 \\
\hline Thiacloprid & 92.1 & 0.004 & 97.1 & 7.1 \\
\hline Metalaxyl & 103.8 & 0.007 & 110.8 & 10.7 \\
\hline Dimethoate & 122.7 & 0.015 & 122.7 & 22.0 \\
\hline
\end{tabular}



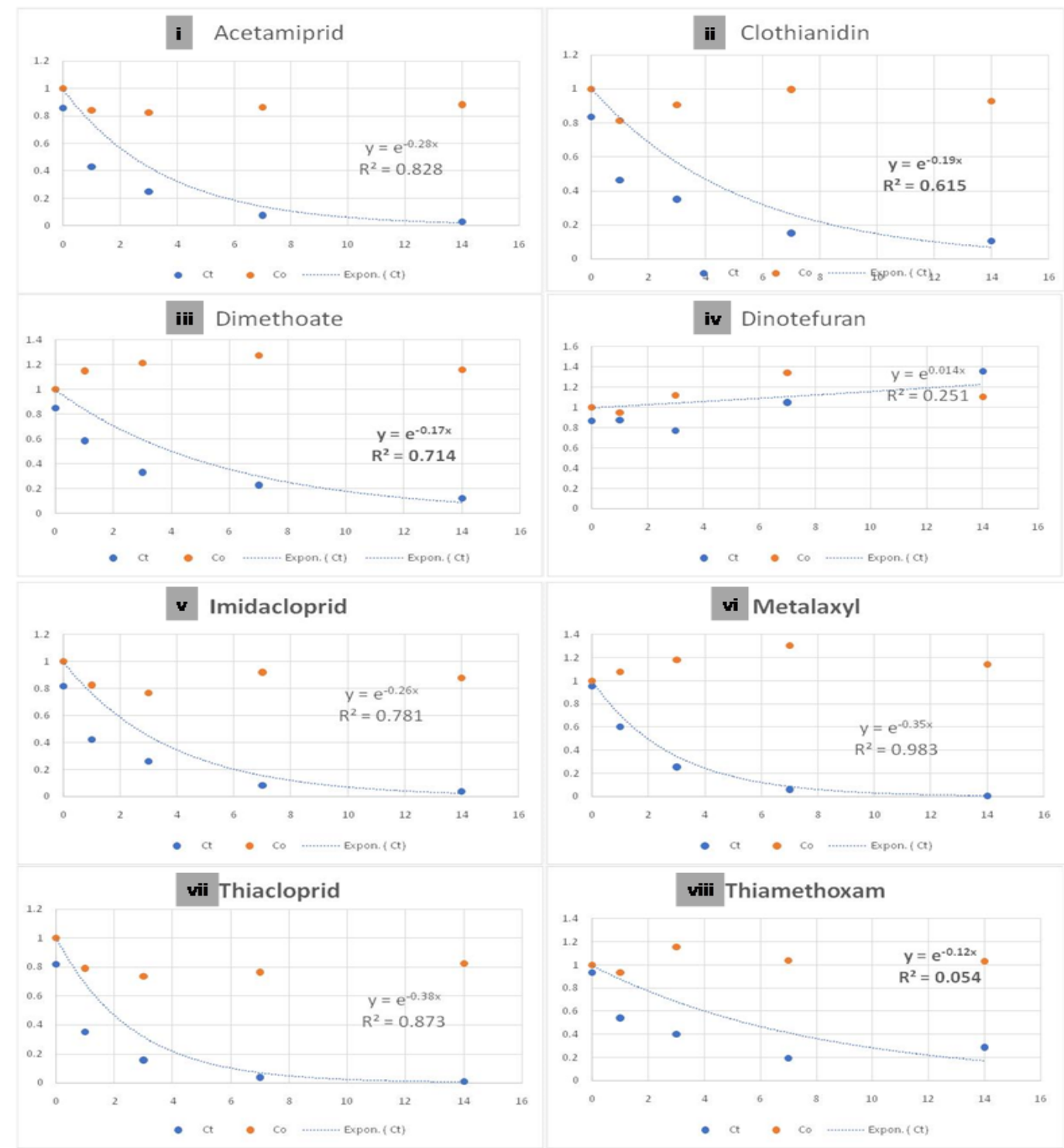

Figure S2: First order kinetics graph over 14-days exposure time for (i) acetamiprid, (ii) clothianidin, (iii) dimethoate, (iv) dinotefuran, (v) imidacloprid, (vi) metalaxyl (vii) thiacloprid, and (viii) thiamethoxam. 
Table S9. Sampling rates $\left(\mathrm{R}_{\mathrm{s}}\right.$ values) of POCIS (Lday $\left.{ }^{-1}\right)$

\begin{tabular}{|l|r|r|r|}
\hline & \multicolumn{1}{|c|}{$\mathbf{k}\left(\mathbf{d a y}^{-1}\right)$} & $\mathbf{R}_{\mathbf{s}}\left(\mathbf{L d a y}^{\mathbf{1}}\right)$ & \multicolumn{1}{l|}{$\mathbf{R 2}$} \\
\hline Target Compounds & & & \\
\hline Acetamiprid & 0.28 & 0.56 & 0.8633 \\
\hline Clothianidin & 0.19 & 0.38 & 0.6216 \\
\hline Dimethoate & 0.17 & 0.34 & 0.4575 \\
\hline Dinotefuran & 0.014 & 0.028 & -1.166 \\
\hline Imidacloprid & 0.26 & 0.52 & 0.7526 \\
\hline Metalaxyl & 0.35 & 0.7 & 0.9288 \\
\hline Thiacloprid & 0.38 & 0.76 & 0.7796 \\
\hline Thiamethoxam & 0.12 & 0.24 & 0.7258 \\
\hline
\end{tabular}

Table S10. Flux estimates of target compounds at (Sites 1 and 2X) in (tonnes x 10-3) day- ${ }^{1}$

\begin{tabular}{|l|c|c|c|c|c|c|}
\hline & \multicolumn{2}{|c|}{ June } & \multicolumn{2}{c|}{ August } & \multicolumn{2}{c|}{ October } \\
\hline Target Compounds & Site 1 & Site 2X & Site 1 & Site 2X & Site 1 & Site 2X \\
\hline & & & & & & \\
$\boldsymbol{\gamma}$-HCH & 3.47 & 4.75 & 0.82 & 0 & 3.6 & 3.85 \\
\hline Dieldrin & 0.82 & 0 & 0 & 2.51 & 2.8 & 0 \\
\hline Imidacloprid & 0 & 0 & 0 & 0.29 & 0.26 & 0 \\
\hline
\end{tabular}

Monthly fluxes were estimated using the average daily discharge over the months of June, August and October for Site 1 and Site 2X along Syr Darya. Average flux for $\gamma$-HCH was maximum and the estimated flux was observed at both the sites except for the month of August at Site 2X. Flux for dieldrin was maximum in October. Imidacloprid was observed only at Site $2 X$ in August and at Site 1 in October. All the other target compounds were not detected at either sites.

\section{References}

Cassada, D. A.; Spalding, R. F.; Cai, Z.; Gross, M. L. (1994) Determination of atrazine, deethylatrazine and deisopropylatrazine in water and sediment by isotope dilution gas chromatography-mass spectrometry. Anal. Chim. Acta 287, 7-15. 